University of Louisville

ThinkIR: The University of Louisville's Institutional Repository

Electronic Theses and Dissertations

8-2017

\title{
Prevention and treatment of familial adenomatous polyposis and colorectal cancer by bilberry-derived anthocyanidins.
}

Ashley M. Mudd

University of Louisville

Follow this and additional works at: https://ir.library.louisville.edu/etd

Part of the Pharmacology, Toxicology and Environmental Health Commons

\section{Recommended Citation}

Mudd, Ashley M., "Prevention and treatment of familial adenomatous polyposis and colorectal cancer by bilberry-derived anthocyanidins." (2017). Electronic Theses and Dissertations. Paper 2801.

https://doi.org/10.18297/etd/2801

This Master's Thesis is brought to you for free and open access by ThinkIR: The University of Louisville's Institutional Repository. It has been accepted for inclusion in Electronic Theses and Dissertations by an authorized administrator of ThinkIR: The University of Louisville's Institutional Repository. This title appears here courtesy of the author, who has retained all other copyrights. For more information, please contact thinkir@louisville.edu. 


\title{
PREVENTION AND TREATMENT OF FAMILIAL ADENOMATOUS POLYPOSIS AND COLORECTAL CANCER BY BILBERRY-DERIVED ANTHOCYANIDINS
}

\author{
By \\ Ashley M. Mudd \\ A Thesis submitted to the faculty of the School of Medicine of the University of Louisville \\ in partial fulfillment of the requirements for the degree of \\ Masters of Science in Pharmacology and Toxicology \\ Department of Pharmacology and Toxicology \\ University of Louisville \\ Louisville, Kentucky \\ August 2017
}





\title{
PREVENTION AND TREATMENT OF FAMILIAL ADENOMATOUS POLYPOSIS AND COLORECTAL CANCER BY BILBERRY-DERIVED ANTHOCYANIDINS
}

\author{
By \\ Ashley M. Mudd \\ A Thesis approved on \\ July 13, 2017 \\ By the following thesis committee: \\ Ramesh C. Gupta, Ph.D. \\ Nejat K. Egilmez, Ph.D. \\ David W. Hein, Ph.D. \\ Radha Munagala, Ph.D. \\ David J. Schultz, Ph.D. \\ Vivek R. Sharma, M.D.
}




\section{DEDICATION}

This thesis is dedicated to my family for all of their support and encouragement and my two 'little scientists'. 


\section{ACKNOWLEDGEMENTS}

I would like to acknowledge and thank my mentor Dr. Ramesh C. Gupta for all of his support, patience and encouragement in all of my scientific endeavors. I would also like to thank Dr. Nejat K. Egilmez and Dr. Tao Gu for all of their help with the animal studies contained within this thesis, their advice, support and encouragement. I would also like to thank my committee members including Dr. Nejat K. Egilmez, Dr. David W. Hein, Dr. Radha Munagala, Dr. David J. Schultz and Dr. Vivek R. Sharma for all of their support. I would also like to thank all of the members of the Gupta lab, 3P Biotechnologies and Egilmez lab for their training, patience and willingness to always help. I would also like to thank Dr. Brian P. Ceresa, Dr. Carolyn M. Klinge and Dr. Robert A. Mitchell for their guidance and feedback with the cell-signaling pathways investigated in this project as well as my proposed PhD. research studies. 


\title{
ABSTRACT \\ PREVENTION AND TREATMENT OF FAMILIAL ADENOMATOUS POLYPOSIS AND COLORECTAL CANCER BY BILBERRY-DERIVED ANTHOCYANIDINS
}

\author{
Ashley Marie Mudd \\ July $13^{\text {th }} 2017$
}

Colorectal cancer (CRC) is the third leading cause of cancer-related deaths within the United States. Familial adenomatous polyposis (FAP) is an inherited disorder which if left untreated will develop into colon cancer. The family of plant-derived compounds, anthocyanins, show significant therapeutic potential against a variety of diseases, however, they are limited by their instability and poor bioavailability. The goal of my Master's research project was to determine whether anthocyanidins (non-glycosylated anthocyanins) are more effective than the native anthocyanins, and whether exosomal formulation of anthocyanidins (ExoAnthos) can enhance therapeutic potency compared with free Anthos against both FAP and CRC. The antiproliferative effects of the native mixture of Anthos isolated from bilberry, with and without exosomal formulation, as well as individual Anthos against APC mutant (HT-29, Caco2), APC wild-type (HCT116) colon cancer cells and CCD-18Co normal colon cells were assessed using an MTT assay. To assess chemopreventive effects, the impact of the Anthos on polyp number was investigated in the $\mathrm{APC}^{\mathrm{Min} /+}$ mouse model for FAP. While therapeutic efficacy of the Anthos treatment on colorectal tumor number was assessed in vivo using an APC ${ }^{\mathrm{Min} /+}$ ETBF mouse tumor model. Early mechanistic work was undertaken to assess the impact of Anthos treatment on EGFR and Src phosphorylation using western blot analysis. Antiproliferation studies showed that ExoAnthos significantly lowered the $\mathrm{IC}_{50}$ compared to free Anthos against colon cancer cells. Anthos treatment led to significant reductions in polyp and tumor counts in vivo. Reduced Src and EGFR phosphorylation was also observed. These results provide a promising outlook on the future of the berry Anthos for treatment and prevention for both FAP and CRC. 


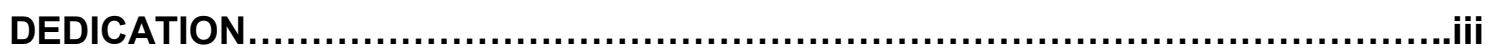

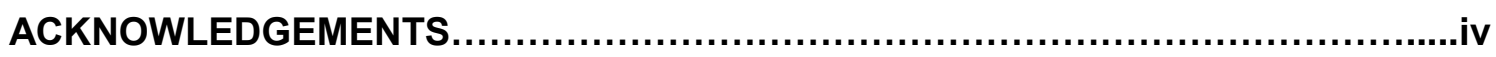

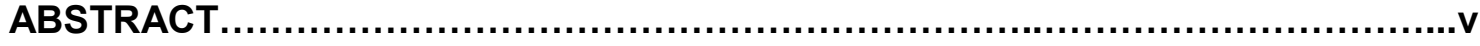

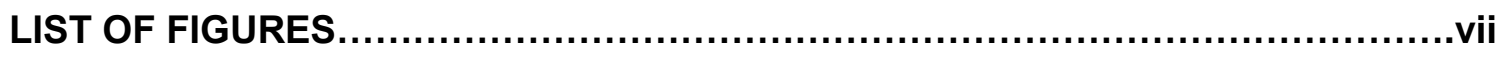

BACKGROUND AND INTRODUCTION

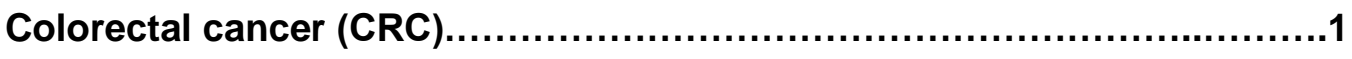

Familial Adenomatous Polyposis (FAP) ........................................

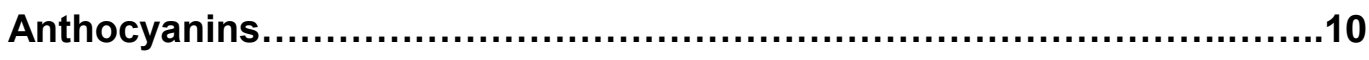

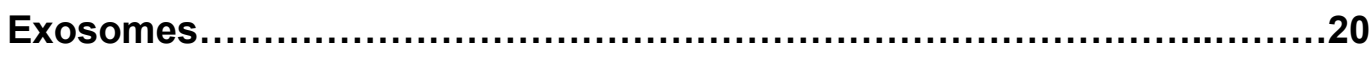

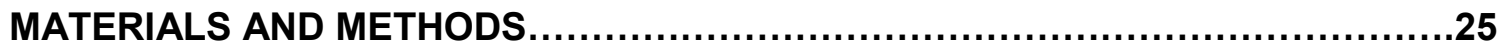

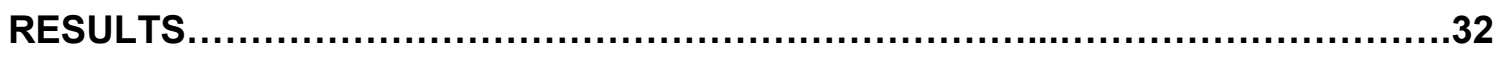

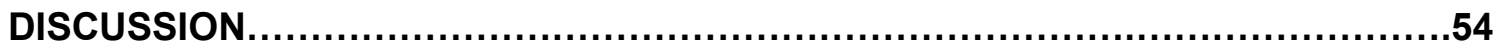

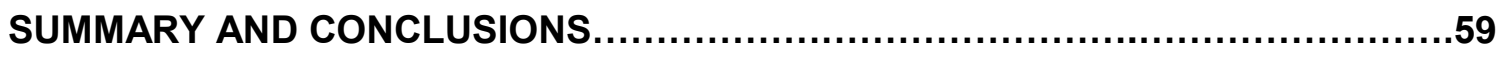

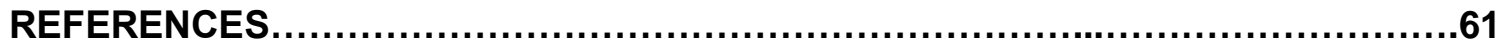

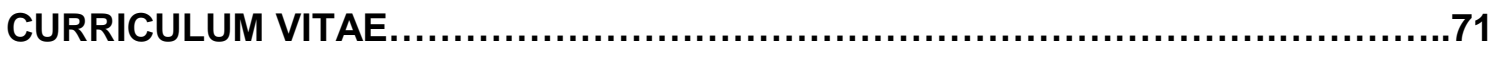




\section{LIST OF FIGURES}

\section{FIGURE}

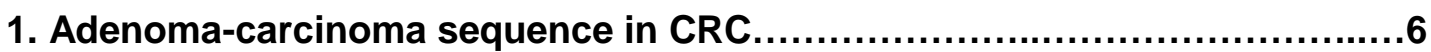

2. Structures for the 5 anthocyanidins..............................................13

3. Classic pathway of exosome formation.............................................21

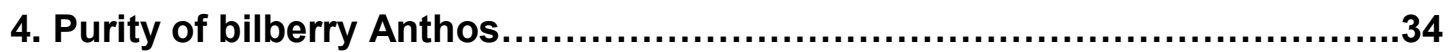

5. Antiproliferative activity of individual Anthos and anthocyanins...............35

6. Antiproliferative activity of individual anthocyanidins.............................36

7. Antiproliferative activity of native bilberry Anthos...............................38

8. Anti-polyp activity of bilberry derived Anthos against intestinal polyps.......40

9. Anti-tumor activity of bilberry derived Anthos against colon tumors..........41

10. Changes in EGFR phosphorylation after treatment with Bilberry Anthos....44

11. Changes in Src phosphorylation after treatment with Bilberry derived

Anthos

12. Morphology and size of milk exosomes and ExoAnthos.........................46

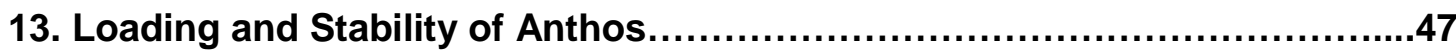

14. Antiproliferative activity of Exosomes against colon normal cells and cancer cell lines .48

15. Antiproliferative activity of Anthos vs. ExoAnthos against colon normal cells and cancer cell lines.

16. Antiproliferative activity of Anthos vs. Milk ExoAnthos and Colostrum ExoAnthos against colon cancer cell line HCT-116. 


\section{BACKGROUND \& INTRODUCTION}

\section{Colorectal cancer}

Colorectal cancer is the third most common form of cancer diagnosed in men and women and the third leading class for yearly cancer-related deaths within the United States. According to the American Cancer Society, an estimated 135,430 individuals will be diagnosed and 50,260 will die from colorectal cancer in the US in 2017 alone. Furthermore, according to the SEER database, in 2014 an estimated 1,317,247 individuals were living with colorectal cancer in the United States. Given the prevalence and lethality of colorectal cancer, there is a great need for investigating not only chemotherapeutic alternatives but also chemopreventive strategies for this disease.

\section{Influences on the development of colorectal cancer}

A wide variety of influences have been found to impact an individual's chance of developing colorectal cancer including age, race, gender [1], lifestyle and diet [2]. The highest incidence rates have been found in North America, Europe, Australia and New Zealand and the lowest incidence rates have been found in Africa and South-Central Asia [3]. Although the incidence of colorectal cancer has been decreasing since the mid to late 1980s for individuals over 55 years old, a recent study has found a rather disconcerting uptick in the colorectal cancer incidence for individuals below 55 years old [4]. A particularly concerning trend was noted for millennials, with individuals born circa 1990 having a risk of developing colon cancer that is double that of an individual born circa 1950 and for rectal cancer the risk was four fold higher. Moreover, a greater number of the younger cases were found in the distal colon as opposed to the proximal colon. This is 
somewhat surprising considering that tumors in the distal colon have been decreasing overall in recent years, while tumors of the proximal colon have become more common in the 55 years or older portion of the population [4]. The exact causes for this recent increase in younger individuals have yet to be defined. However, a number of factors have been shown to contribute to the development of colorectal cancer. The below summary provides an overview of some of the key environmental as well as genetic factors that are related to the topic of this thesis and that have been found to impact the development of colorectal cancer.

\section{The impact of diet and lifestyle on CRC risk}

The important role that diet and lifestyle play not only on one's overall health but on the chance of developing colorectal cancer has been found in a number of studies. Furthermore, it should be noted that chronic inflammation has been shown to be a significant etiological factor in the development of colorectal adenocarcinoma [5]. It has been shown in both males and females that a link exists between consuming a high inflammatory diet, i.e. a diet rich in animal fat, alcohol et cetera and low in fruits and vegetables, and developing colorectal cancer [2]. Moreover, results from the same study also supported the benefits of an anti-inflammatory diet, which include plant based foods which are a rich source of phytochemicals, over a pro-inflammatory diet, which includes fried foods, highly processed food etc., as a means of decreasing the risk of developing CRC [2]. Additionally, coffee which contains a variety of bioactive compounds including polyphenols, melanoidins, diterpenes, and caffeine is believed to also lower the risk of developing CRC [6]. Epidemiological studies comparing coffee drinkers vs. non-drinkers showed a $26 \%$ lower odds of developing CRC [6]. There also appeared to be a dose dependent trend for both colon and rectal cancers. It was also noted that decaffeinated as well as boiled coffee showed an inverse association (OR, 0.82; $95 \% \mathrm{Cl}$ : 0.68-0.99; 
$\mathrm{P}=0.04)$ and $(\mathrm{OR}, 0.82 ; 95 \% \mathrm{Cl}: 0.71-0.94 ; \mathrm{P}=0.004)$ respectively [6]. In addition to coffee, it has also been shown that regular green tea consumption (at least three times per week for a minimum of 6 months), which is a rich source of antioxidant tea polyphenols, reduces the risk of colorectal cancer ( $\mathrm{HR}=0.54,95 \% \mathrm{Cl}: 0.34-0.86)$. Furthermore, it was noted that as green tea consumption was increased risk of colorectal cancer decreased $\left(P_{\text {trend }}=0.01\right)$ $[7]$.

In addition to dietary influences, another important factor that must be considered is the long term use of medications such as statins, aspirin and non-aspirin nonsteroidal antiinflammatory drugs which are also believed to lower the risk of developing CRC. For example statins which are believed to inhibit 3-hydroxy-3methylglutaryl coenzyme A (HMG-CoA) reductase which is overexpressed in colorectal cancer cells were associated with a 47 percent relative reduction in risk of CRC [8]. Whereas, NSAIDS, which are believed to act by inhibiting cyclooxygenase-2, which has been shown to be upregulated in colorectal cancer, was shown to yield an adjusted relative risk of 0.5 (95\% confidence interval of 0.4-0.7) [9].

Great insight into the complex exchange between the individual and their surroundings and their associated risk of developing colorectal cancer has been gained by the sheer depth of epidemiological studies conducted to date. However, the above findings should be interpreted with caution due to the dangers of inferring causation from association. The above studies provide a promising foundation from which the topic of my thesis, i.e. the use of anthocyanidins as both a chemotherapeutic as well as preventative agent, has been constructed.

\section{Outline of mutations found to be linked with development of CRC}

In addition to the extrinsic influences discussed above, another key participant in the dialogue of colorectal carcinogenesis is genetics. Some of the key genes that have been 
found to influence the development of $\mathrm{CRC}$ include TP53, $\operatorname{KRAS/BRAF}[10,11]$, EGFR/PTEN [12-14], SMAD7 [15], MLH1 [16], MUTYH [17] and the adenomatous polyposis coli (APC) gene [18-21].

Both sporadic and hereditary cases of colorectal cancer have been attributed to mutations in the adenomatous polyposis coli (APC) gene. It has been noted that $34-70 \%$ of sporadic colon cancer cases feature inactivating mutations in APC particularly in the mutation cluster region, with genetic aberrations such as deletions, insertions, point and missense mutations detected in the mutation cluster region in $72 \%$ of the patients studied [18]. It has also been shown that individuals with APC gene mutations possess a significantly increased risk for colorectal cancer (pooled OR of 1.42 and $95 \% \mathrm{Cl}$ of $1.16-1.74$ with a $\mathrm{P}$ value of 0.00085 ) [19]. Furthermore, it should be noted that APC mutations appear to be more likely to occur with TP53 mutations (OR $3.513,95 \% \mathrm{Cl}$ of $1.212-10.184$ ) and KRAS mutations (OR 1.995, 95\% Cl of 0.607-6.554) [21].

The important role that the above mutations, especially APC, play in the development of CRC has been historically well documented. Moving forward, the characterization or "fingerprinting" of an individual's specific mutations will be key in developing personalized therapeutic regimens for each patient.

\section{Pathways of genomic instability that can lead to CRC}

It is commonly accepted knowledge that three main molecular pathways of genomic instability are involved in the development of $\mathrm{CRC}$ and include: the chromosomal instability pathway $(\mathrm{CIN})$, the mismatch repair deficient or microsatellite instability pathway (MSI), and the $\mathrm{CpG}$ island methylator phenotype (CIMP) pathway.

The CIN pathway, which was originally elucidated by Fearon and Vogelstein in 1990, is believed to be responsible for most cases of CRC and is observed in $65-70 \%$ of sporadic 
CRC's [22]. These cases feature characteristic loss of heterozygosity (LOH), subchromosomal genomic amplifications and widespread aneuploidy. In Fearon and Vogelstein's seminal 1990 article, they proposed a multistep model for colorectal carcinogenesis [23] which is shown in Figure 1. The initiating event in adenoma formation is the inactivation of the Adenomatous Polyposis Coli (APC) tumor suppressor gene which is followed by activating mutations of KRAS. Additional mutations in TGF- $\beta$ [24], PIK3CA [25], and TP53 [26] pathways then drive the subsequent malignant transformation. It should be noted that although APC mutations serve as the initiating event in human and mouse models, mutational activation of KRAS is unable to initiate cancer in vivo and only when combined with mutant APC will mutant KRAS promote tumor progression, thus supporting Fearon's multistep model [27].

The Microsatellite instability (MSI) pathway accounts for approximately $10-20 \%$ of all CRCs [28]. Although the MSI pathway was originally elucidated for individuals with familial Lynch syndrome, most CRCs with MSI are sporadic. In fact, only $3 \%$ of all CRCs come from Lynch syndrome families [29]. MSI tumors caused by Lynch syndrome are associated with germline mutations in DNA mismatch repair (MMR) genes and often have KRAS mutations, but never have BRAF mutations.

Lynch syndrome tumors also typically occur in younger individuals and typically have a better prognosis than non-MSI tumors [30]. Approximately $50 \%$ of sporadic cases of MSI have BRAF mutations and are associated with CIMP, unlike Lynch syndrome tumors. As can be expected, sporadic cases of MSI-associated CRCs typically occur in older individuals[29]. 


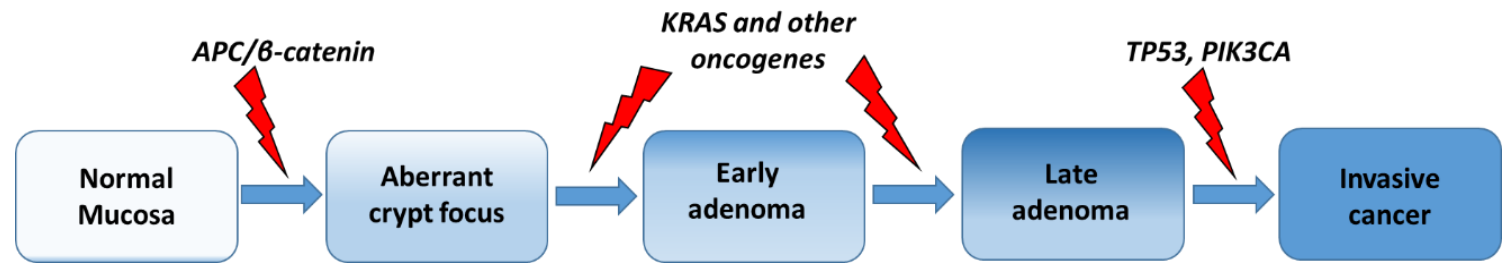

Figure 1: Adenoma-carcinoma sequence in the development of colorectal cancer 
The $\mathrm{CpG}$ island methylator (CIMP) is observed in approximately $30 \%$ of CRC cases [31]. As its name implies, the CIMP pathway promotes epigenetic instability and enables sporadic cancers to methylate the promoter regions of key tumor suppressor genes thereby effectively inactivating their expression [32]. In fact it is present in all tumors with MLH1 aberrant methylation [33]. CIMP positive tumors typically exhibit specific clinicopathological features such as proximal location and tend to be more common in older women, are often MSI and poorly differentiated. They also tend to have a distinct molecular profile which features low TP53 and high BRAF mutation rates [34]. Furthermore, cases of colorectal cancer that develop via the CIMP pathway tend to develop from sessile serrated adenomas rather than adenomatous polyps [35].

\section{Current standard of care}

As with most cancers current treatment options for individuals diagnosed with colorectal cancer include one or more of the following options: surgery, radiation therapy, nontargeted chemotherapy, or targeted therapy.

According to the American Cancer Society, drugs currently approved by the U.S. FDA for the treatment of colorectal cancer include: capecitabine, fluorouracil (5-FU), irinotecan, oxaliplatin, and trifluridine/tipiracil. One or more of these chemotherapeutic drugs are most often given over the course of treatment with more common treatment regimens with these drugs including: 5-FU, 5-FU with a vitamin called leucovorin which improves the efficacy of 5-FU [36], capecitabine, 5-FU with leucovorin and oxaliplatin (FOLFOX), 5-FU with leucovorin and irinotecan (FOLFIRI), capecitabine with either irinotecan (XELIRI or CAPIRI) or oxaliplatin (XELOX or CAPEOX), and irinotecan alone. A variety of negative side effects are associated with taking the standard chemotherapeutic drugs including: nausea, vomiting, fatigue, diarrhea, suppression of bone marrow, immunosuppression, and liver damage $[37,38]$. Given the current limitations and negative side effects 
associated with the current standard of care, additional treatment options are greatly needed.

In addition to non-targeted chemotherapeutic treatment options, targeted therapies are also common, including: bevacizumab, regorafenib, ramucirumab and ziv-aflibercept, which are antiangiogenesis therapies, and cetuximab and panitumumab which are antiEGFR therapies [39]. Although, one of the key benefits of targeted therapy is the reduction in off-target side-effects, they are also accompanied with side-effects including gastrointestinal perforation, arterial thromboses which include strokes and myocardial infractions [40].

Treatment options for individuals diagnosed with colon cancer are typically dependent upon their specific stage. Additional factors such as age and other health problems are also considered for the optimal treatment plan [41]. In most cases, when the cancer has not spread to distant sites, surgery is typically the first main treatment. For more advanced stage cancers, an adjuvant chemotherapy may also be recommended. Adjuvant chemotherapy may be recommended as early as stage II, but is more typically recommended beginning in stage III [41]. For the more advanced stage IV cases of colon cancer where the disease has spread to distant organs and tissues, a key component of the treatment is chemotherapy since in most cases surgery will not cure these individuals. Since the early 2000's, 5 new drugs have been approved for the treatment of stage IV colon cancer. These drugs fall into one of the three following classes: multi-kinase inhibitors, anti-angiogenic (Bevacizumab, Ziv-aflibercept), or EGFR blockers (Cetuximab, panitumumab) [42].

Key limitations in the current standard of care include, but are not limited to the following areas: off-target side effects, the current gap that exists in adjuvant therapy for stage I and especially stage II cancers of the colon, and limitations in treatment options for older 
individuals. Given these limitations, research investigating alternative preventative treatment options is of great importance.

\section{Familial Adenomatous Polyposis (FAP)}

The majority of colorectal cancer cases originate from previously benign adenomatous polyps. This process of transformation from benign polyp to malignancy typically takes decades to occur, with approximately $85 \%$ of colorectal cases occurring after the age of 55 years, according to data acquired by the U.S. preventive services task force. A small subset of CRC cases stem from familial syndromes such as Lynch syndrome, FAP, attenuated FAP (AFAP), MUTYH-associated polyposis (MAP) and rare syndromes such as hyperplastic polyposis, Peutz-Jeghers syndrome (PJS) and juvenile polyposis syndrome $[43,44]$.

FAP is an autosomal dominant pre-cancerous colorectal condition with an incidence at birth of around 1/8,300 [45]. FAP occurs with equal frequency in both males and females and accounts for less than $1 \%$ of colorectal cases [45]. The disease may begin as early as the teenage years, with colon cancer developing on average by the age of 39 years old. Furthermore, approximately $7 \%$ of individuals with FAP will develop CRC by the time they reach 21 years old and $95 \%$ of FAP sufferers will develop CRC by the time they reach the age of 50 [46]. FAP is caused by mutation(s) in the adenomatous polyposis coli (APC) gene. The APC gene, which is located on chromosome $5 q 21$ is a tumor suppressor gene that encodes for a $312 \mathrm{kDa}$ protein with 2843 amino acids. It is expressed in a variety of fetal and adult tissues including colorectal epithelium as well as mammary [47].

Mutation(s) in the APC gene, $60 \%$ of which are nonsense mutations, have been shown to accelerate the initiation of the adenoma-carcinoma sequence since the inactivation of APC serves as the initial step in the development of CRC in FAP [45]. The APC protein serves 
as a scaffolding protein which affects cell adhesion and migration. The mammalian form of APC contains multiple binding domains including an oligomerization domain, an armadillo repeat domain, a repeat domain consisting of between 15-20 residues which is important for binding to $\beta$-catenin, SAMP repeats which are important for axin binding, a basic domain that is responsible for microtubule binding, and finally C-terminal domains, which bind the proteins, EB1 and HDLG [48].

APC interacts with a variety of other key proteins such as the Wnt/Wg pathway members, $\beta$-catenin and axin, the Rac guanine-nucleotide-exchange factor (GEF) Asef1, the cytoskeletal regulators EB1 and IQGAP1, as well as microtubules [49]. Mutations in APC lead to the accumulation of $\beta$-catenin in the cytoplasm where it binds and activates the Tcell factor (TCF) and lymphoid enhancer factor (LEF) families of transcription factors altering the expression of genes that encode for the metalloprotease matrilysin, ephrins, cyclin D1 and the proto-oncogene c-myc which in turn lead to changes in cellular proliferation, differentiation and migration [50].

If left untreated, individuals with FAP will develop colorectal cancer by their forties [51]. As discussed above, APC plays a key role in the multi-step model of colorectal cancer proposed by Fearon and Vogelstein (Figure 1). The disease is characterized by the development of hundreds to thousands of adenomatous colon polyps. Currently, the only approved primary modality of treatment for FAP is prophylactic cancer-preventive colorectal surgery. Given the lack of non-invasive treatment options and the role of FAP in $\mathrm{CRC}$ development, additional treatment options are of great need.

\section{Anthos: a promising treatment for FAP and colorectal cancer}

Several plant-derived compounds such as quinine, codeine, paclitaxel, apomorphine, have been an invaluable source of medicines for humans throughout history. One 
particular family of compounds that has sparked recent interest is flavonoids and members such as anthocyanins.

\section{Flavonoids}

One particular class of relevance is the flavonoids which is one of the largest groups of secondary metabolites with well over 6000 molecules [52]. Compounds classified as flavonoids, which all share a common core 15-carbon skeleton, can be divided into 6 major classes: flavanols, flavonols, flavonones, flavones, isoflavones and anthocyanins. Flavonoids are commonly synthesized by plants in order to fulfil a variety of protective functions ranging from as a chromatic attractant for pollinators, as a deterrent for pests, as a protectant against UV-B, as well as an antimicrobial agent [53].

\section{Anthocyanins and anthocyanidins}

Found in dark-colored vegetables, fruits, grains and flowers, anthocyanins, which comes from the Greek words Anthos for flower and kyanos for blue, provide the characteristic red, purple and blue hues to eggplant, blueberry, black rice and black sesame seeds. Over 600 structurally distinct anthocyanins have been identified in nature [54, 55]. It should be noted that anthocyanins are known as anthocyanidins when non-glycosylated. Of the seventeen anthocyanidins found in nature, only six, including the glycosylated forms of: cyanidin (Cy), delphinidin (Dp), petunidin (Pt), peonidin ( $\mathrm{Pn})$, pelargonidin $(\mathrm{Pg})$ and malvidin (Mv), are widely distributed [56]. The above anthocyanidins are typically bonded to glucose, galactose, arabinose, rhamnose, and xylose in either a mono-, di- or trisaccharide form. An additional layer of complexity is provided by the fact that the sugar moieties can also be acylated by various aromatic or aliphatic acids. The various combinations/permutations of anthocyanidins and their pendant sugars vary from plant to 
plant. Importantly, it should be highlighted that the active component of the compounds is the central anthocyanidin moiety.

The core structure of anthocyanidin (Figure 2) is composed of an aromatic ring A that is bonded to a heterocyclic ring $\mathrm{C}$ containing oxygen that is bound via carbon to a third aromatic ring $\mathrm{B}$. The substituted flavonoids contain a flavylium cation, which due to its conjugated double bonds, absorbs light with a characteristic peak range between 500 $550 \mathrm{~nm}$. The specific hue(s) associated with each anthocyanin depend upon the degree of hydroxylation and type/number of substitutions. A total of 17 anthocyanidins have been isolated to date [57].

The specific anthocyanin fingerprint varies between each type of fruit, vegetable, grain or flower. For example fruits such as red currents and elderberry contain primarily cyanidin, whereas blueberry, bilberry and jamun contain 5 anthocyanidins- cyanidin, delphinidin, petunidin, peonidin and malvidin, all in their glycosylated forms. Bilberry in particular contains a native mixture of delphinidin, cyanidin, malvidin, peonidin, and petunidin in a relative ratio of $33: 28: 16: 16: 7$ [58]. As noted above, in addition to variations in the core anthocyanidin structure, variations in the pendant sugar moieties also varies from plant to plant. For example, even though red currant and blackcurrant are closely related, red currant contains mainly mono- and diglycosides, whereas black currant contains primarily rutinosides and only a minor glycoside component [59].

\section{Role of anthocyanins within plants}

Within plants, anthocyanins accumulate in vacuoles of a variety of cells in both vegetative as well as reproductive organs. Most of the 17 anthocyanidins isolated to date are found only in the reproductive structures of the plants whereas only six anthocyanidins (cyanidin, peonidin, delphinidin, petunidin, malvidin and pelargonidin) have been found in the vegetative organs [60]. 


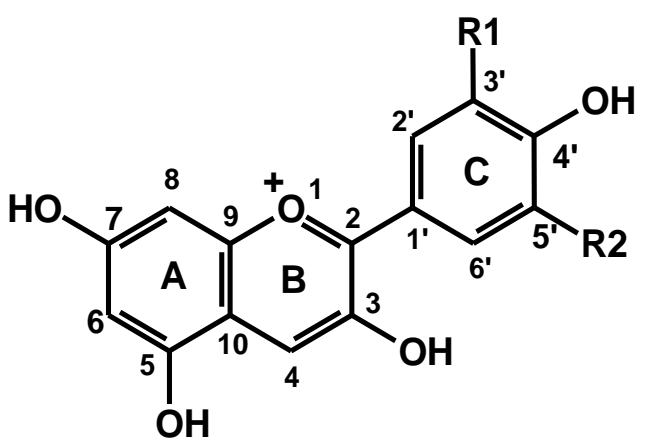

\begin{tabular}{l|l|l} 
& $\mathbf{R}_{\mathbf{1}}$ & $\mathbf{R}_{\mathbf{2}}$ \\
\hline Delphinidin & $-\mathrm{OH}$ & $-\mathrm{OH}$ \\
\hline Cyanidin & $-\mathrm{OH}$ & $-\mathrm{H}$ \\
\hline Peonidin & $-\mathrm{OCH}_{3}$ & $-\mathrm{H}$ \\
\hline Petunidin & $-\mathrm{OH}$ & $-\mathrm{OCH}_{3}$ \\
\hline Malvidin & $-\mathrm{OCH}_{3}$ & $-\mathrm{OCH}_{3}$ \\
\hline
\end{tabular}

Figure 2: Structures for the five anthocyanidins (the active moiety of anthocyanins) contained in blueberry and bilberry 
Furthermore, anthocyanins are synthesized in the branch of the flavonoid biosynthetic pathway that is involved in the synthesis of isoflavonoids and flavonols [57]. Anthocyanins are thought to play a variety of different functions within plants ranging from as antioxidants, sunscreens, and even as metal-chelating agents and in delaying foliar senescence under conditions of mineral imbalance or macronutrient deficiency [57]. Given their beneficial roles in plants, one can easily hypothesize that benefits may be gained from their consumption by humans.

\section{Anthocyanin absorption, stability, and digestion}

Absorption of anthocyanidins and anthocyanins by gut epithelial cells occurs via different mechanisms due to the structural differences. Due to the hydrophilicity added by the sugar residues on anthocyanins they must utilize active transport mechanisms whereas anthocyanidins, which do not have a sugar residue and are more hydrophobic are able to be passively absorbed by gut epithelial cells [61]. In fact, the hydrophobicity of a compound, expressed in terms of its partition coefficient (log octanol/water) is often used as a predictive means to determine the ability of a compound to passively diffuse across a biological membrane. Interestingly, it has been found that nonenzymatic deglycosylation does not occur in the human body for polyphenols such as quercetin [62]. Additionally, only polyphenols with attached glucose, arabinose or xylose and not rhamnose moieties can serve as potential substrates for human $\beta$-glucosidases. Therefore, rhamnose

moieties can only be cleaved once they reach the colon where they can serve as a substrate for bacterial a-rhamosidases [61]. This limitation may have important ramifications for the activity of rhamnose-containing anthocyanins in diseases of the small intestine or in diseases where digestive transport time is expedited such as inflammatory bowel disease (IBD). 
Another important topic that must be addressed in the discussion of anthocyanin metabolism is the role of deconjugation and reconjugation reactions. Although anthocyanins do not appear to undergo as extensive of metabolism as other flavonoids, it will be discussed for completion since it occurs and is a variable that must be considered [63]. Following hydrolysis, the free aglycones undergo metabolic processing in the form of methylation, sulfation, glucuronidation or a combination of the above reactions $[64,65]$. Based on the structural differences between anthocyanins versus anthocyanidins, the impact that conjugation has on the biological properties of the circulating metabolites is evident.

Overall, one should understand that a competition between the uptake of anthocyanidins and the excretion of more hydrophilic anthocyanins as well as their conjugated counterparts exists. Therefore, one could posit that by administering anthocyanidins either in their pure form or by nano-delivery systems, one would enhance their therapeutic potential in the clinical setting.

\section{Data from In vitro work}

A variety of in vitro studies have been conducted in order to investigate the impact that anthocyanins derived from various sources have on colon cancer cell lines. Berry extracts containing anthocyanins isolated from cowberry, strawberry, bilberry, and blueberry have been shown to inhibit the proliferation of the colon cancer cell line HCT116 [66]. Furthermore, anthocyanin rich extracts derived from fruits including bilberry (Vaccinium myrtillus L.), grape (Vitis vinifera), and chokeberry (Aronia meloncarpa E.) have been shown to inhibit the growth of the colon cancer cell line HT-29 cells but not the nontumorigenic NCM460 colon cells [67]. 
A variety of potential mechanisms have been suggested in the literature. For instance, anthocyanins isolated from the grape, Vitis coignetiae Pulliat were shown to induce caspase-dependent apoptotic cell death, activate p38-MAPK and suppress Akt in HCT116 colon cancer cells [68]. Moreover, pelargonidin, found in a variety of berries such as strawberries and pomegranates, was shown to inhibit proliferation of the colon cancer cell line HT-29 and induce apoptosis and G2/M cell cycle arrest by the intrinsic apoptotic pathway [69]. Additionally, delphinidin, found in fruits like blueberry, has also been shown to induce apoptosis and G2/M cell cycle arrest in HCT116 colon cancer cells [70]. The mechanism by which delphinidin led to G2/M arrest and apoptosis in HCT116 cells is believed to be due to suppression of the NF-KB pathway [70]. Anthocyanins and anthocyanidins have also been shown to induce significant oxidative DNA-strand cleavage in the presence of dithiotheritol (DTT), but not DMSO, which serves as a free radical scavenger, at physiological $\mathrm{pH}$. It was further hypothesized that at $\mathrm{pH} 7.5$, the quinones formed from anthocyanins and anthocyanidins autoxidize to yield hydrogen peroxide [71]. $\mathrm{Fe}^{3+}$ is believed to increase anthocyanin-induced cleavage since when it is reduced it is able to stimulate the production of hydroxyl radicals from hydrogen peroxide. The resulting hydroxyl radical, rather than hydrogen peroxide, is believed to induce the cleavage of DNA [71]. Only at high concentrations were anthocyanins also shown to inhibit topoisomerase relaxation [71].

\section{Data from in vivo studies}

The beneficial effects of anthocyanins shown in vitro have also been shown to exist in vivo. For instance, the anthocyanin-rich soybean fraction containing cyanidin-3-glucoside, delphinidin-3-glucoside and petunidin-3-glucoside, was shown to significantly decrease the number of intestinal tumors in $\mathrm{Apc}^{\mathrm{Min} /+}$ mice fed a $0.5 \%$ anthocyanin-rich extract compared to control animals [72]. Furthermore, mucosal expression of cytosolic 
phospholipase $A_{2}$ and cyclooxygenase-2, which are both involved in inflammatory response, were significantly decreased in mice treated with $0.5 \%$ anthocyanin-rich extract [72]. Additionally, an in vivo study in $\mathrm{Apc}^{\mathrm{Min} /+}$ mice using $0.3 \%$ oenocyanin, which contains the 3-glucosides of delphinidin, cyanidin, petunidin, peonidin, and malvidin extracted from grape pomace, showed a reduction in adenoma burden and reduction in proliferation index in colonic adenomatous crypts [73]. A reduction in the expression of Akt, which is involved in a variety of cellular processes including glucose metabolism, apoptosis, cellular proliferation, transcription and migration, was also observed in $0.3 \%$ oenocyanin-treated mice [73]. Interestingly, oenocyanin anthocyanins and their metabolites were not found in the plasma but rather only in the urine and intestine [73]. Moreover, in a mouse model of colitis, dextran sulfate sodium (DSS) induced histological damage and weight loss were significantly improved in mice administered a red raspberry anthocyanin-rich fraction [74]. In the same study, anti-inflammatory properties were shown in vivo with overall reductions in the expression of cyclooxygenase-2 (COX-2), interleukin-1 beta (IL-1ß), IL-6 and inducible nitric oxide (iNOS) in red raspberry anthocyanin-rich fraction treated RAW264.7 cells [74].

A study assessing the impact of dietary cyanidin-3-glucoside and an anthocyanin mixture from bilberry on the development of adenomas in an Apc ${ }^{\mathrm{Min} /+}$ mouse model for FAP [75] showed that ingestion of cyanidin-3-glucoside or a bilberry derived anthocyanin mix led to a reduction in adenoma load in a dose dependent fashion. It should be noted that although significant reductions in adenoma numbers were seen for cyanidin-3-glucoside $(p<0.001)$ and Mirtoselect bilberry anthocyanins $(p<0.05)$, the doses that were used were $0.3 \%$ of the diet which is equivalent to $450 \mathrm{mg} / \mathrm{kg} /$ day or $2.6 \mathrm{~g} / 80 \mathrm{~kg}$ human dosage, when the authors extrapolated using the dose/surface area comparison between species [76]. When the Mirtoselect native bilberry mixture was extrapolated back to the amount of fresh 
berries that would need to be consumed, it was concluded that an individual would need to consume $\sim 740 \mathrm{~g}$ of fresh bilberry a day [75]. Given the large nature of the dose used in the study, which is further complicated due to the presence of high sugar content (about $60 \%$ in blueberry), it is clear that one would need to lower the dose by identifying the active principles in order to be a clinically-viable option.

\section{Data from clinical trials}

A limited number of clinical trials have been undertaken to assess the impact that anthocyanins, taken in the form of either berry powder or as an anthocyanin-rich standardized bilberry extract, has on colorectal cancer. The first study was a clinical trial assessing whether an anthocyanin-rich standardized bilberry extract (Mirtocyan) administered to patients $(1.3,2.8$ or $5.6 \mathrm{~g}$, containing $0.5-2.0 \mathrm{~g}$ anthocyanins) daily for 7 days before surgery would induce pharmacodynamics changes that would be in agreement with chemopreventive efficacy [77]. Results from the study showed that a 7\% decrease in proliferation was observed in tumor tissues taken from patients when compared to their pre-intervention values. Another clinical trial investigating the impact of freeze-dried blackberry powder (60g/day, for 1 to 9 weeks) in colorectal cancer patients showed beneficial changes in GM-CSF and IL-8, markers for proliferation and apoptosis respectively [78].

A clinical trial assessing the impact of black raspberry $(\mathrm{BRB})$ powder on biomarkers of colorectal tumor development showed that the methylation patterns of three Wnt inhibitors including WIF1, SFRP2, SFRP5 and the developmental regulator PAX6a were protectively modulated in normal and in colorectal tumor tissues in patients receiving the black raspberry powder $(60 \mathrm{~g} / \mathrm{d})$ for an average of 4 weeks. Furthermore, the protective modulation of methylation was associated with decreased expression of the enzyme that transfers methyl groups to the cytosine nucleotides in genomic DNA, DNA (Cytosine-5-)- 
Methyltransferase 1 (DNMT1) [79]. Interestingly, the authors also noted that black raspberry powder decreased $\beta$-catenin as well as protectively modified Ki-67, TUNEL, CD105, as well as DNMT1 in colorectal tissues from the 20 patients. CD105 and DNMT1 were also found to be modulated in adjacent normal tissues. The impact on $\beta$-catenin and E-cadherin expression was also shown to be dose dependent, with the high dose $(\sim 4$ weeks) BRB powder treatment yielding greater impact than the low dose ( 2 weeks) BRB powder treatment [79].

In addition to studies on colorectal cancer, anthocyanin-rich bilberry extract has also been shown to reduce the amount of pro-inflammatory cytokines including TNF- $\alpha$ and IFN- $\gamma$ in colon biopsies from patients with ulcerative colitis (UC). Furthermore, serum levels from UC patients that were successfully treated with anthocyanin-rich bilberry extract had enhanced levels of immunoregulatory IL-10 and the Th-17 cell specific cytokine IL-22 and reduced levels of TNF- $\alpha$ and IFN-y [80]. In another clinical trial testing the impact of a standardized anthocyanin-rich bilberry extract on UC disease activity showed that after 6 weeks of treatment, $63.4 \%$ of patients achieved remission and $90.9 \%$ of patients showed a response. It was also noted that fecal calprotectin levels were also decreased during the treatment, which further suggests that intestinal inflammation was reduced [81].

It should be noted that all of the anthocyanin-mediated colorectal cancer clinical trials published to date have been conducted using anthocyanins rather than anthocyanidins. Although the bioavailability of anthocyanins is very low in the plasma $(<1 \%)$, greater bioavailability has been found in colonic tissues [82]. This suggests that they may have greater potential since they can directly interact with the colon tissue. Additionally, one can posit that additional benefits in uptake, if administered in the aglycon form (ie as anthocyanidins) or by utilizing a nano drug delivery vehicle such as bovine milk derived exosomes (i.e. ExoAnthos). 


\section{Exosomes}

\section{Size, history, sources}

Exosomes are defined as membrane-bound vesicles that range in size from $30-100 \mathrm{~nm}$, in diameter, feature a density in sucrose gradients of $1.13-1.19 \mathrm{~g} / \mathrm{ml}$, are highly enriched with tetraspanin molecules and are of endocytic origin [83]. Exosomes were discovered in 1983 by Pan and Johnstone. In 1989, Pan and Johnstone named the vesicles exosomes [84]. Since their identification, exosomes have been isolated from essentially all biological fluids such as saliva, peripheral blood, cerebrospinal fluid (CSF), urine, sweat, malignant effusions and milk [85].

\section{Exosome formation}

Exosomes are initially formed via a process of endocytosis, with the internalization of the cell membrane to yield endosomes (Figure 3). Following the formation of endosomes, many small vesicles are formed inside the endosome by invagination of parts of the endosomal, multi-vesicular body (MVB), membrane. The MVBs then fuse with the cell membrane thereby releasing the intraluminal vesicles into the extracellular space. Following their release, these vesicles are referred to as exosomes. 


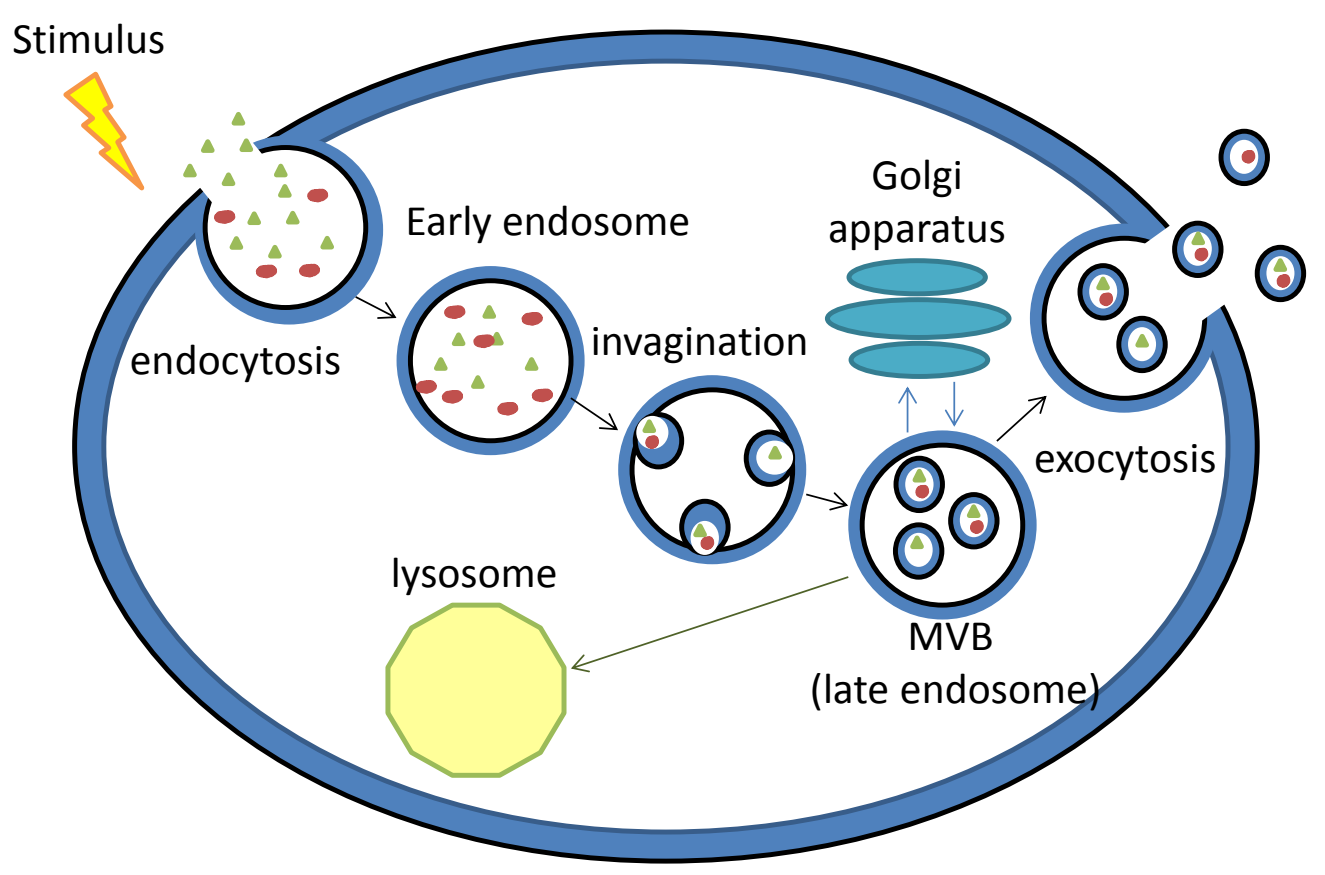

Figure 3: Classic pathway of exosome formation. After endocytosis, endosomes are formed via the internalization of the cell membrane (sidedness noted in the diagram as blue for the initial internal face and black for the initial external face). A process of invagination of the endosome yields smaller bodies inside the MVB, which can proceed to processing via the golgi apparatus, be released via exocytosis yielding exosomes or be degraded by the lysosome. 


\section{Exosome composition}

Exosomal membranes are primarily composed of lipids and proteins and are enriched with lipid rafts [86]. The lipid composition of exosomes is distinctively rich in cholesterol, ceramide, sphingomyelin, and phosphatidylserine[87]. However, exosomes contain minimal to no lysobisphospatidic acid (LBPA), which distinguishes them from MVBs' intraluminal vesicles (ILVs) [87]. Furthermore, the fatty acids in exosomes tend to be saturated or monounsaturated, which in addition to the high concentration of cholesterol is believed to lead to the lateral segregation of these lipids into exosomes during their formation [88]. Results from proteomic studies suggest that exosomes contain specific proteins from endosomes, plasma membrane, and cytosol [89]. Examples of proteins from the endosome include Alix, Tsg101, Rab GTPase, SNAREs Annexin and Flotillin. Proteins originally associated with the plasma membrane include tetraspanins, such as CD63, CD81 and CD37. It should be noted that exosomes contain very few proteins from other intracellular organelles such as the nucleus, mitochondria and Golgi [87].

\section{Exosome cargo}

In addition to proteins, exosomes have been found to carry as cargo within their lumen, that include mRNA, miRNA, small noncoding RNA species such as structural RNAs, tRNA fragments, vault RNA, small interfering RNAs, RNA transcripts that overlap with protein coding regions and repeat sequences [88]. More recent data indicate the presence of some DNA as well [90]. The RNA cargo contained within exosomes can either be taken up by neighboring cells or transported by the circulating exosomes and taken up by distant cells. Ultimately, the RNA cargo in exosomes is believed to function as a form of genetic exchange between cells [86]. 


\section{Exosome role in cell to cell communication}

Once called the "garbage bag" of cells, exosomes have been found to play an important role in cell to cell communication. After finding that mRNAs and miRNAs were present in exosomes derived from mast cells, it was also found that the mRNA in these exosomes were transported to recipient cells and following uptake were translated into proteins thus providing evidence for the ability of exosomes to transfer of genetic material [91]. It was noted that not all mRNAs that were abundant in the secreting cells were packaged into exosomes thereby suggesting that specific targeting machinery for mRNAs may exist [91]. It has also been shown that tumor derived exosomes can both suppress the function of immune cells by promoting the differentiation of regulatory $\mathrm{T}$ lymphocytes or by inducing apoptosis of activated cytotoxic $T$ cells [92]. Exosomes can also induce immune responses by transferring tumor antigens to dendritic cells and to present tumor antigens [93]. Interestingly, it has been found that exosomes can fuse especially well with the plasma membranes under acidic conditions mimicking those of the cancer cell microenvironment [94].

\section{Exosomes as therapeutics}

Special interest in the application of exosomes for diagnostic as well as drug delivery purposes has recently taken root within the scientific community. A key area of research within our laboratory is in utilizing exosomes as a drug delivery vehicle. Prior to the work conducted in this lab, the primary source of exosomes for drug delivery purposes was from cell culture media and serum. In order to overcome the obvious limitations posed by these sources such as quantity, safety, cost and translatability, our lab pioneered the use of exosomes derived from bovine milk $[95,96]$. Not only does bovine milk provide a scalable source of exosomes, it also exhibits cross-species tolerance. Furthermore, no adverse immune or inflammatory responses have been found [97]. 
Exosomes derived from raw bovine milk can effectively deliver a variety of both hydrophilic as well as lipophilic compounds such as curcumin, withaferin A (WFA), paclitaxel, celastrol and doxorubicin. Moreover, tumor targeting of the exosomes with folic acid was shown to increase biological efficacy. Exosomal formulations containing WFA, celastrol, or curcumin have shown increased efficacy over drug alone in both in vitro and in vivo against lung and breast cancer [95, 96]. Prior to the body of studies contained within this manuscript no experiments were undertaken with colon cancer. In addition to the role of the exosomes as a drug delivery vehicle, they are also believed to deliver an additional "payload" of their own. For instance, our lab has identified the presence of immune-related miRNAs such as miR-146a, $-155,-181$ a and -223 in bovine milk derived exosomes [95].

The overarching goal of my Master's work has been to investigate the use of bilberry derived Anthos as both a chemotherapeutic as well as chemopreventive agent in colorectal cancer as well as FAP. I have also undertaken preliminary studies with ExoAnthos, with the ultimate goal of utilizing this nano-delivery system in future work. 


\section{METHODS \& MATERIALS}

\section{Anthocyanins and anthocyanidins}

The individual anthocyanins, delphinidin 3,5-diglucoside, malvidin 3,5-diglucoside, petunidin 3,5-diglucoside and cyanidin 3-monoglucoside were a kind gift from Dr. Inder P. Singh of the National Institute of Pharmaceutical Education and Research (S. A. S. Nagar, India). The individual Anthos, delphindin, cyanidin, petunidin, malvidin, peonidin and pelargonidin, were purchased from Chromadex (Irvine, CA). The native Anthos mixture isolated from bilberry with purity of $>80 \%$ was generously provided by $3 \mathrm{P}$ Biotechnologies, Inc. (Louisville, KY).

\section{Isolation of bilberry-derived Anthos}

The native Anthos mixture from bilberry obtained from 3P Biotechnologies (Louisville, KY) were further enriched using C18 Sep-Pak cartridges (Waters, Milford, MA, USA). Anthos were eluted with acidified $(0.1 \% \mathrm{HCl})$ ethanol. The enriched extract was then dried using a Savant Speed-Vac (Thermo Scientific, USA) and stored at $-20{ }^{\circ} \mathrm{C}$. Purity was verified using HPLC-PDA-UV. Briefly, $15 \mu$ l samples were analyzed using a Shimadzu Premier C18 reverse-phase column (250x4.6 mm i.d., $5 \mu \mathrm{m})$. Mobile phase A was composed of water: formic acid: acetonitrile (87:10:3) and mobile phase B was composed of water: formic acid: acetonitrile (40:10:50). The flow rate was $0.6 \mathrm{ml} / \mathrm{min}$ and the gradient condition was $0-5 \min 5 \%$ B; $5-15 \min 15 \%$ B; $15-20 \min 25 \%$ B; $20-30 \min 35 \%$ B; $30-40$ min $45 \%$ B; $40-45 \min 100 \% \mathrm{~B} ; 45-50 \mathrm{~min} 5 \% \mathrm{~B}$. Anthos were detected at $520 \mathrm{~nm}$ by PDA-UV and total Anthos concentration was calculated using a standard curve. The reference 
compounds were purchased from Chromadex (Irvine, CA) and Cayman Chemical Company (Ann Arbor, MI).

\section{Isolation of milk-derived exosomes}

Exosomes were isolated from raw bovine milk using differential centrifugation using the method described by Munagala et al., [95] Briefly, in order to remove casein aggregates, fat globules as well as other debris, the milk was first centrifuged at 20,000xg for 30 minutes at $4 \stackrel{\circ}{\circ}$ using a TA-10259 rotor and Allegra 25R centrifuge (Beckman Coulter, Fullerton, CA). The resulting whey was then filtered by passing through grade 90 cheesecloth. In order to remove microvesicles and large particles, the whey was then subsequently centrifuged at $100,000 \times \mathrm{xg}$ for 60 minutes at $4{ }^{\circ} \mathrm{C}$ using an Optima LE-80K Ultracentrifuge (Beckman Coulter, Fullerton, CA). About two thirds of the resulting supernatant was then carefully transferred to new tubes, discarding the bottom one third of the supernatant and the pellet, and further centrifuged at $135,000 \times \mathrm{g}$ for 90 minutes at $4 \stackrel{\circ}{\circ}$ using an Optima LE-80K Ultracentrifuge (Beckman Coulter, Fullerton, CA). After discarding the supernatant, the resulting exosome pellet was washed three times with PBS. The pellets were pooled and suspended in PBS (final protein content adjusted to 6 $\mathrm{mg} / \mathrm{ml}$ ) using a Potter homogenizer. The homogenized suspensions were then filtered through a $0.22 \mu \mathrm{m}$ filter for sterilization. Exosomal preparations were then assessed for size distribution, morphology, and protein markers using Zetasizer (Malvern Instruments Ltd., Malvern, Worchestshire, UK), atomic force microscopy (Oxford Instruments, Goleta, CA) and Western blot, respectively. Bovine colostrum-derived exosomes, prepared the same as the milk exosomes, were provided for the studies as a kind gift from 3P Biotechnologies (Louisville, KY). 


\section{Protein determination}

Protein estimation for exosomal preparations was assessed using a bicinchoninic acid (BCA) assay (Thermo Scientific, Rockford, IL). In order to determine protein concentration, diluted exosomal preparations were compared, in triplicate, to a serially-diluted bovine serum albumin (BSA) standard curve.

\section{Loading of the Anthos onto the exosomes (ExoAnthos)}

The native mixture of bilberry Anthos was loaded onto exosomes by mixing Anthos (dissolved in ethanol and water) with the exosomes in a 1:5 (Anthos:Exosomal protein) ratio at room temperature $\left(22^{\circ} \mathrm{C}\right)$. Unbound Anthos and any protein coagulates were removed using low speed centrifugation $(10,000 \times g$ for $10 \mathrm{~min})$, and the exosomes that were loaded with Anthos were then collected by ultracentrifugation (135,000 x $g$ for $1.5 \mathrm{~h})$. The pellet was then suspended in PBS and passed through a $0.22 \mu \mathrm{m}$ filter and stored at $-80 \stackrel{\circ}{ } \mathrm{C}$.

\section{Analysis of drug loading}

In order to determine the practical drug load of Anthos in the ExoAnthos formulation, the protein and Anthos concentrations were measured. Briefly, a $50 \mu$ laliquot of ExoAnthos formulation was mixed with $950 \mu \mathrm{l}$ of acidified ethanol $(0.1 \% \mathrm{HCl})$. The precipitated proteins were separated by centrifugation $(10,000 \times \mathrm{g}$ for 10 minutes). The Anthos contained in the supernatant was then analyzed using a SpectraMax M2 spectrometer (Molecular Devices, Sunnyvale, CA). Anthos were detected at $520 \mathrm{~nm}$ and total Anthos concentration was calculated using a standard curve. Reference Anthos were acquired from Chromadex (Irvine, CA). Anthos concentrations were confirmed via HPLC-PDA. The pelleted exosomal proteins were determined by the BCA method described above. The

percent drug load when then calculated by dividing the amount of Anthos by exosomal 
proteins $x 100$ [95]. The proportionate loading of individual Anthos was confirmed using HPLC-DAD.

\section{Characterization of Exosomes and ExoAnthos}

The size of control colostrum exosomes and ExoAnthos, which were diluted in PBS to 1 $\mathrm{mg} / \mathrm{ml}$, were determined using a Zetasizer (Malvern Instruments Ltd, Malvern, Worcestershire, UK). Morphology of the exosomes and ExoAnthos was determined by atomic force microscopy (AFM). Briefly, exosomes and ExoAnthos were diluted with deionized water to $10 \mu \mathrm{g} / \mathrm{ml}$. A $2 \mu \mathrm{l}$ aliquot of each sample was then placed on a silica wafer and air dried for 30 min. Images were captured using an Asylum MF-3D AFM (Oxford Instruments, Goleta, CA) in tapping mode using aluminum-coated silicon probes. The amplitude, topographic height and phase retraces were imaged with a fixed force $(<1 \mathrm{nN})$ at a scanning rate of $1 \mathrm{~Hz}$. Images were processed using IGOR software.

\section{Cells, culture conditions and treatments}

The APC wild-type HCT 116 (ATCC® CCL-247 ${ }^{\text {TM}}$ ) and APC mutant Caco-2 (ATCC® HTB$37^{\mathrm{TM}}$ ) colon cancer cell lines were acquired from American Type Culture Collection (Manassas, VA, USA). The APC mutant colon cancer cell line HT-29 (ATCC® HTB38D ${ }^{\mathrm{TM}}$ ) was a kind gift from Dr. Nobuyuki Matoba (University of Louisville). HCT-116 and HT-29 cells were maintained in McCoy's 5A medium (Gibco, Grand Island, NY) supplemented with $10 \%$ FBS, $100 \mathrm{U} / \mathrm{ml}$ penicillin and $100 \mu \mathrm{g} / \mathrm{ml}$ streptomycin in a humidified atmosphere containing $5 \% \mathrm{CO}_{2}$ at $37^{\circ} \mathrm{C}$. Caco-2 and CCD-18Co cells were maintained in Mema (Gibco, Grand Island, NY) supplemented with 20\% FBS, $100 \mathrm{U} / \mathrm{ml}$ penicillin and $100 \mathrm{ug} / \mathrm{ml}$ streptomycin in a humidified atmosphere containing $5 \% \mathrm{CO}_{2}$ at $37^{\circ} \mathrm{C}$. 


\section{Measurement of cell viability}

The cytotoxicity of the colostrum exosomes, the bilberry Anthos and ExoAnthos in colon cancer cell lines was assessed by enzymatic reduction of the tetrazolium dye MTT. Briefly, $3.0 \times 10^{3}$ cells/well were grown in a 96-well tissue culture plates and were then exposed to varying concentrations of the Anthos, ExoAnthos, the exosomes or vehicle control 24 hours after seeding. After $72 \mathrm{~h}$ treatment, cells were incubated with $5 \mathrm{mg} / \mathrm{ml}$ MTT reagent for $2 \mathrm{~h}$. The resulting formazan crystals were then solubilized in DMSO and spectrophotometrically measured at $570 \mathrm{~nm}$ (Bio-rad, Philadelphia, PA, USA). IC $_{50}$ values were then determined using Calcysyn software version 2.1 (Biosoft, Cambridge, England).

\section{Western-blot analysis}

For western-blot analysis, $50 \mu \mathrm{g}$ of protein was resolved using gel electrophoresis and electrotransferred to polyvinylidene difluoride membranes by semi-dry transfer (Biorad Trans-blot SD, Hercules, CA). Blots were blocked with 4\% dry powder milk or BSA for $1 \mathrm{~h}$ and then incubated with primary antibodies at $4^{\circ} \mathrm{C}$ overnight and secondary antibodies conjugated to peroxidase for $1 \mathrm{~h}$ at room temperature. Blots were then developed with an

ECL detection system. Densitometric analysis was then performed using ImageJ 1.x software [98].

\section{Animal model for FAP and CRC}

$\mathrm{Apc}^{\mathrm{Min} /+}$ mice are often used to study FAP and CRC. The mice exhibit a germline nonsense mutation at codon 850 of the APC gene, which causes the spontaneous development of polyps predominantly in the small intestine by the age of $10-12$ weeks. 


\section{ETBF}

Enterotoxigenic Bacteriodes fragilis (ETBF) has been found to exist asymptomatically in $12.4 \%$ of individuals and in $27 \%$ of individuals with diarrhea symptoms [99]. It is well known as a global cause of diarrheal disease that is accompanied by colitis in both humans and animals. The pathogenicity associated with ETBF is due to the secretion of a $20 \mathrm{kDa}$ zincdependent metalloprotease toxin, $B$. fragilis toxin (BFT), which binds to colonic epithelial cells and leads to the cleavage of E-cadherin, which is a tumor suppressor protein and the secretion of interleukin-8 [100]. This ultimately leads to the stimulation of proliferation and migration of human colon cancer cells [101]. Furthermore, BFT has also been shown to induce pro-inflammatory cytokine secretion by further activating the NFKB pathway [101].

\section{In vivo CRC studies}

Animal experiments were performed in agreement with an approved protocol by the Institutional Animal Care and Use Committee at the University of Louisville. Breeding colonies were established by Dr. Nejat K. Egilmez's lab [102] at the University of Louisville using $\mathrm{C} 57 \mathrm{BL} / 6 \mathrm{~J} \mathrm{Min} /+\left(\mathrm{Apc}^{\mathrm{Min} /+}\right)$ mice which were originally attained from Jackson Laboratories (Bar Harbour, ME, USA). Mice were genotyped for the APC mutation using PCR according to the protocol outlined by Jackson Laboratories. Mice were fed a standard chow diet and received water ad libitum for the duration of the study and were maintained on a standard light/dark cycle. At 5-6 weeks age, animals were administered antibiotic and 4 days later they were administered ETBF to promote tumorigenesis. One week following ETBF inoculation, animals began their respective treatment regimen. Two studies were performed to test the impact of the Anthos on tumor number. In the first study male Apc ${ }^{\mathrm{Min} /+}$ mice were orally administered (by gavage) $20 \mathrm{mg} / \mathrm{kg}$ Anthos or vehicle control. Animals were treated 5 times a week for 4 weeks. Animals were euthanized in the fed state at 12 
weeks and colon tumors were counted. For the second study female $\mathrm{Apc}^{\mathrm{Min} /+}$ mice were orally administered (by gavage) $40 \mathrm{mg} / \mathrm{kg}$ Anthos or vehicle control. Animals were treated 3 times a week for 4 weeks. Animals were euthanized in the fed state at 11-12 weeks and colon tumors were counted.

\section{In vivo FAP study}

Animal experiments were performed in agreement with an approved protocol by the Institutional Animal Care and Use Committee at the University of Louisville. Breeding colonies were established by Dr. Nejat K. Egilmez's lab [102, 103] at the University of Louisville using C57BL/6J Min/+ $\left(\mathrm{Apc}^{\mathrm{Min} /+}\right)$ mice which were originally attained from Jackson Laboratories (Bar Harbour, ME, USA). Mice were genotyped for the APC mutation using PCR according to the protocol outlined by Jackson Laboratories. Mice were fed a standard chow diet and received water ad libitum for the duration of the study and were maintained on a standard light/dark cycle. Treatments began when animals were 8-9 weeks old. Male $(n=4)$ and female $(n=4) \mathrm{Apc}^{\mathrm{Min} /+}$ mice were orally administered (by gavage) $40 \mathrm{mg} / \mathrm{kg}$ Anthos or vehicle control. Animals were treated 3 times per week for 5 weeks. Animals were euthanized at 13-14 weeks. Following fixation of intestines using formalin, intestinal polyps were counted using a microscope (Leica EZ4, Wetzlar, Germany) by four different experienced individuals after blinding the samples.

\section{Data analysis}

Statistical analysis was performed using Graph Pad Prism statistical software version 4.03 (La Jolla, CA). Student's t-test was used for both animal studies. $\mathrm{IC}_{50}$ values were determined using CalcuSyn software version 2.1 (Biosoft, Cambridge, England). 


\section{RESULTS}

\section{Purity of bilberry-derived Anthos}

Prior to performing any experiments with the Anthos, we first determined the purity of each Anthos preparation. HPLC-DAD analysis yielded a chromatogram (Figure 4) with five peaks featuring retention times that matched in retention times with the reference Anthos, delphinidin, cyanidin, petunidin, peonidin, and malvidin. The bilberry Anthos mixture used in these experiments were confirmed to have a purity greater than $96 \%$ and an average purity of $98 \%$.

\section{Anti-proliferative effects of anthocyanins versus Anthos on colon cancer cells}

In order to determine whether a difference exists between the activities of Anthos versus anthocyanins (delphinidin, cyanidin, delphinidin 3,5-diglucoside, cyanidin 3-glucoside, and cyanidin 3,5-diglucoside) in colon cancer cells, we compared the anti-proliferative activity of two individual Anthos, delphinidin and cyanidin, with their respective anthocyanins, in HCT-116 colon cancer cells. As shown in Figure 5, a clear benefit is derived from the cleavage of the sugar moiety from the anthocyanin component. The greatest advantage in the reduction of $\mathrm{IC}_{50}$ is shown for delphinidin which yielded a greater than 6-fold reduction when the sugar moiety was absent. A similar although slightly lower reduction was observed for cyanidin versus cyanidin 3-glucoside, and cyanidin 3,5-diglucoside, with 2- and nearly 5-fold reductions, respectively. The difference in the anti-proliferative activities for the Anthos versus their respective anthocyanins is most likely due to the differences in size and partition coefficient associated with the possession of the sugar 
moiety presumably affecting their cell uptake. Furthermore, it should be noted that little difference was observed for mono versus di-glycosylated forms of cyanidin. Ultimately, the absence of the sugar moiety enables anthocyanidins to be passively absorbed by the gut epithelial cells [61].

\section{Anti-proliferative effects of Anthos on colon cancer cells}

After confirming that Anthos yielded greater antiproliferative properties than anthocyanins we next set out to determine the relative anti-proliferative activity of the individual Anthos in colon cancer cells. We then measured antiproliferative activity for the available four Anthos, delphinidin, petunidin, malvidin, cyanidin and compared them with the native bilberry Anthos mixture in HCT-116 and HT-29 colon cancer cells. As shown in Figure 6 and Table 1 the lowest $\mathrm{IC}_{50}$ was achieved by delphinidin $(23 \mu \mathrm{M})$, followed by petunidin, malvidin, and cyanidin in HCT-116 cells. A slightly different trend was observed for HT-29 cells with delphinidin and petunidin yielding the lowest $\mathrm{IC}_{50}$ value of $68 \mu \mathrm{M}$ followed by cyanidin and malvidin. Overall, it was noted that the HCT-116 was more sensitive than the HT-29 cells to all the Anthos tested.

\section{In vitro toxicity study with Anthos in normal colon cells}

Prior to testing Anthos in an in vivo model, we first assessed if Anthos presented any toxicity to normal colon CCD-18Co cells. Comparison of the selectivity index values calculated by comparing Anthos treated CCD-18Co normal colon cells with HT-29 and HCT-116 colon cancer cells yielded values of 9 and 14 for HT-29 and HCT-116 colon cancer cells, respectively (Figure 7). These values were well above the recommended minimal SI value of 3 that is used to determine whether a drug selectively targets cancer cells over normal cells. Therefore, given the in vitro selectivity results we decided that Anthos were selective toward cancer cells and were would be promising to test against FAP and CRC mouse models. 


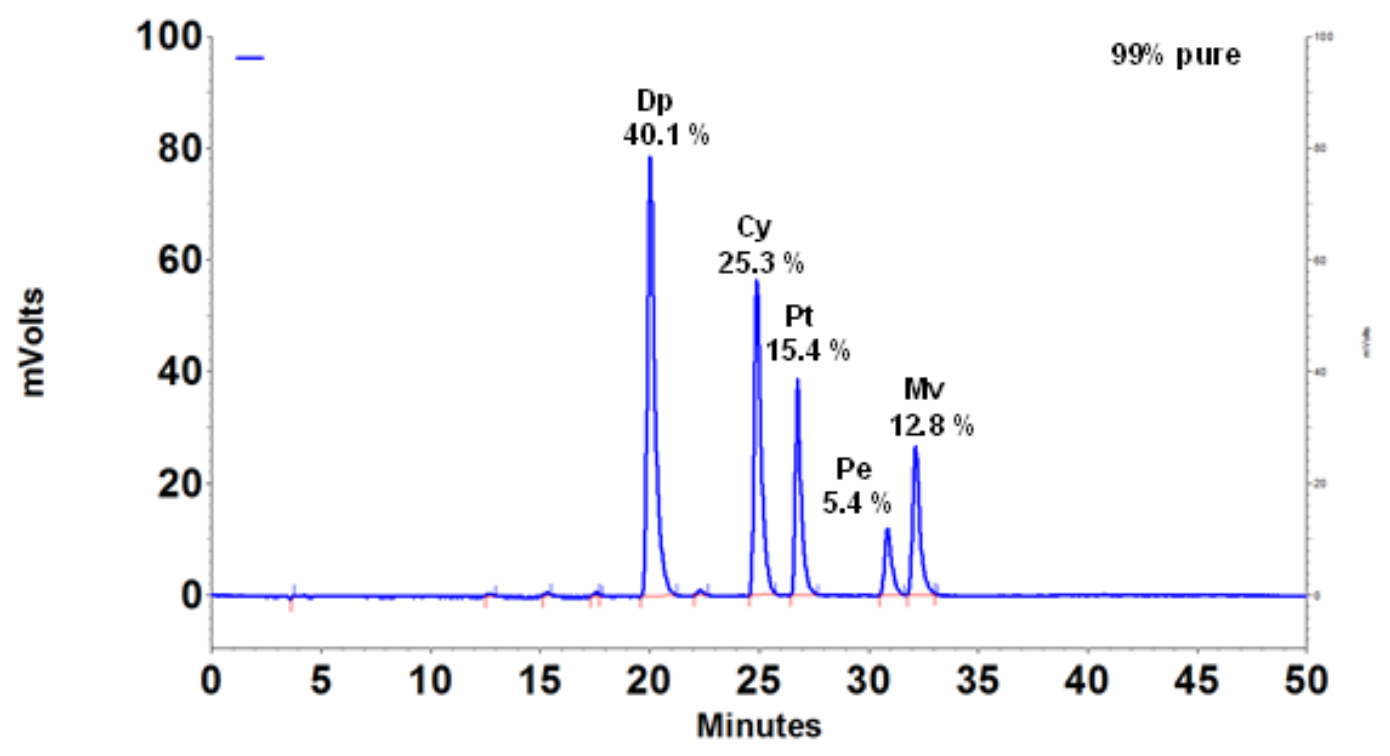

Figure 4 Representative chromatogram of C18 enriched bilberry-derived Anthos: HPLC profile of native mixture of bilberry-derived anthocyanidins including delphinidin (Dp), cyanidin (Cy), petunidin (Pt), peonidin ( $\mathrm{Pe})$, and malvidin (Mv). The purity was verified to be greater than $96 \%$ for all Anthos samples used in the studies included in this thesis. 

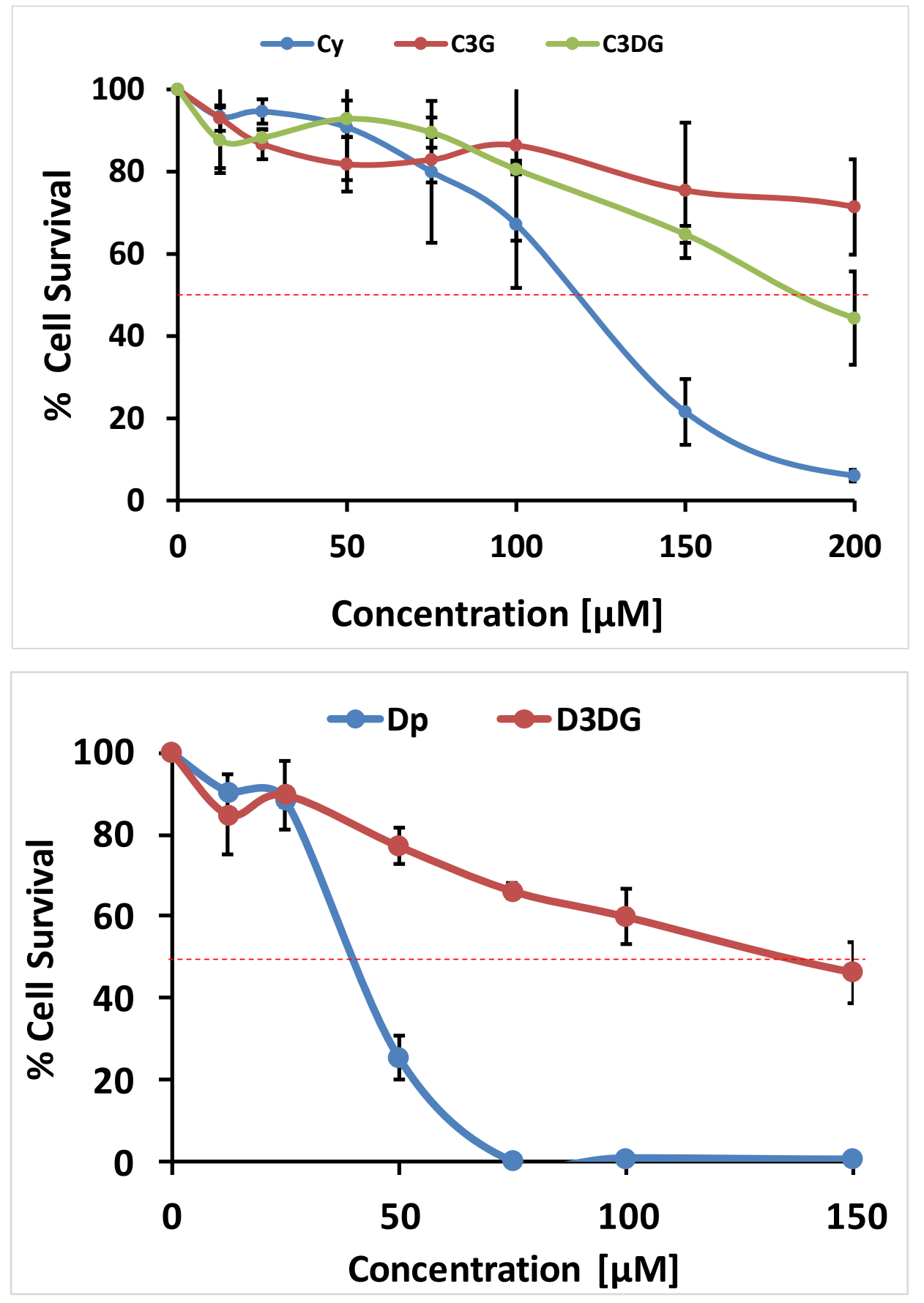

Figure 5 Antiproliferative activity of individual anthocyanidins and their anthocyanin counterparts against colon cancer cell line HCT-116: Colon cancer cell line HCT 116 was treated with various concentrations of the individual anthocyanidins cyanidin (Cy) or delphinidin (Dp) and their anthocyanin counterparts cyanidin 3-glucoside (C3G), cyanidin 3,5-diglucoside (C3DG) or delphinidin 3,5-diglucoside (D3DG) respectively for $72 \mathrm{~h}$ and the effect on cell growth inhibition was assessed using an MTT assay. Data represent average $\pm S D(n=3)$. 

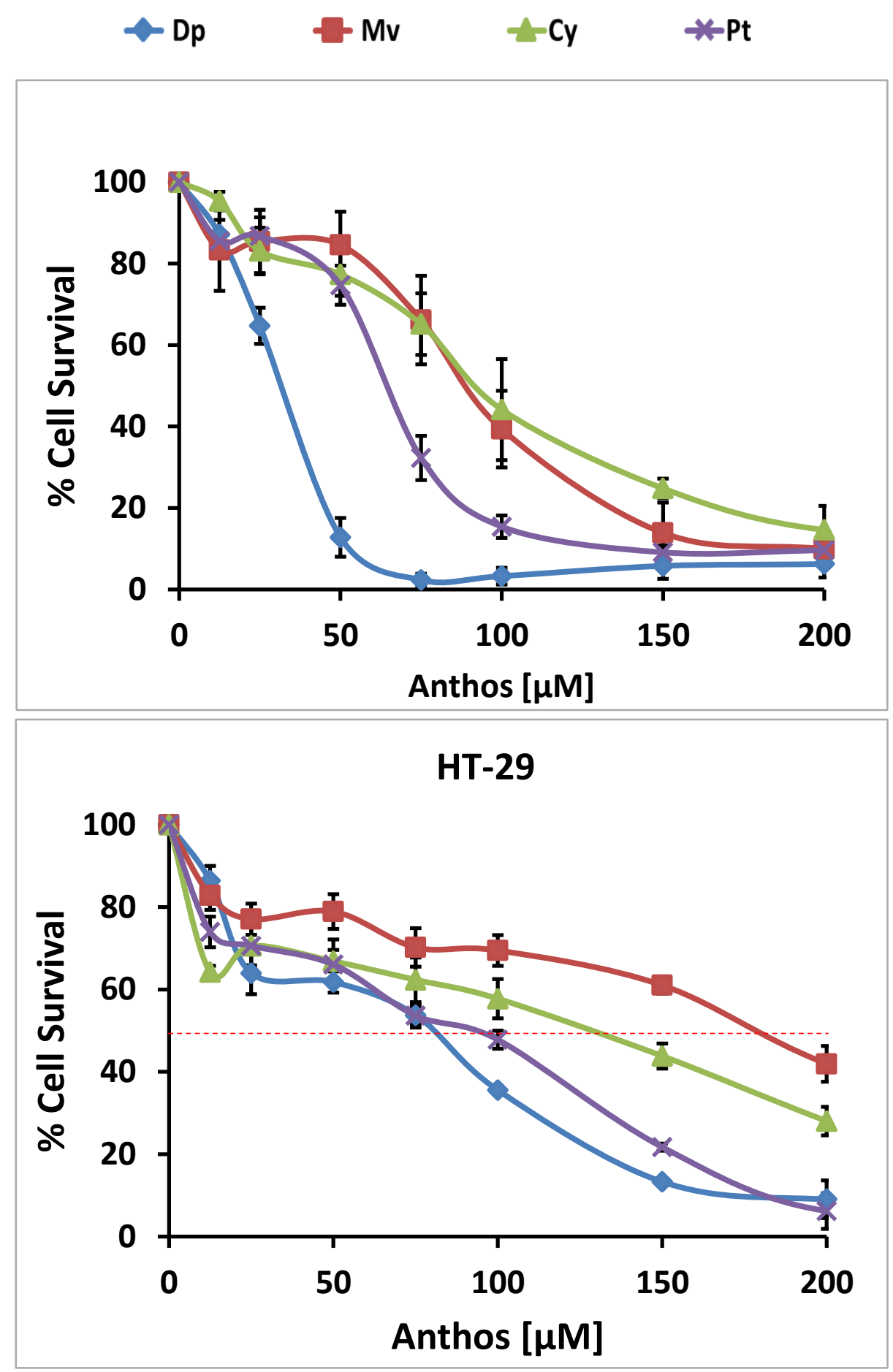

Figure 6 Antiproliferative activity of individual anthocyanidins against colon cancer cell lines: Colon cancer cell lines HCT116 and HT-29 were treated with various concentrations of individual anthocyanidins including cyanidin (Cy), delphinidin (Dp), malvidin (Mv) and petunidin (Pt) for 72 $h$ and the effect on cell growth inhibition was assessed using an MTT assay. Data represent average $\pm \operatorname{SEM}(n=3-4)$. 


\begin{tabular}{|c|c|c|}
\hline Cell line & $\begin{array}{c}\text { HCT116 } \text { IC }_{\text {50 }} \\
{[\mu \mathrm{M}]}\end{array}$ & $\begin{array}{c}\mathbf{H T}^{-29} \mathbf{I C}_{\mathbf{5 0}} \\
{[\boldsymbol{\mu M}]}\end{array}$ \\
\hline $\mathbf{D p}$ & 23 & 68 \\
\hline Cy & 84 & 103 \\
\hline $\mathbf{P t}$ & 53 & 68 \\
\hline $\mathbf{M v}$ & 66 & 156 \\
\hline
\end{tabular}

TABLE 1: Antiproliferative activity of individual anthocyanidins against colon cancer cells. Values listed for the four anthocyanidins tested including cyanidin (Cy), delphinidin (Dp), malvidin (Mv) and petunidin (Pt). 


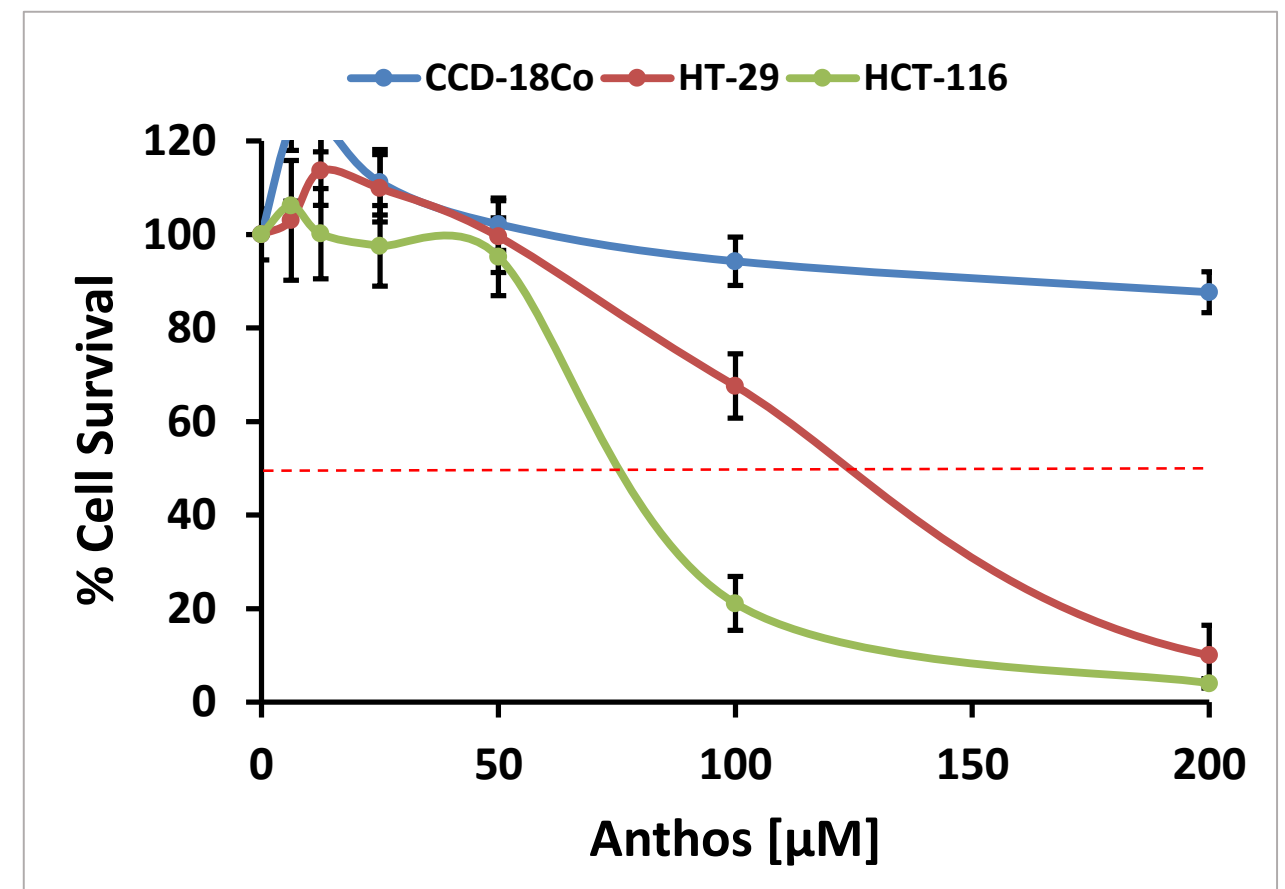

Figure 7 Antiproliferative activity of native bilberry Anthos mixture against colon normal cells and cancer cell lines: Colon normal cells CCD-18Co and colon cancer cell lines HCT-116 and HT-29 were treated with various concentrations of bilberry-derived Anthos for $72 \mathrm{~h}$ and the effect on cell growth inhibition was assessed using an MTT assay. Data represent average $\pm S E M(n=4)$. 
Impact of Anthos treatment on polyp development in $\mathrm{Apc}^{\mathrm{Min} /+}$ mice FAP model

In order to determine if Anthos treatment beneficially impacts intestinal polyp number in vivo, $\mathrm{Apc}^{\mathrm{Min} /+}$ mice were treated with $40 \mathrm{mg} / \mathrm{kg}$ Anthos three times per week for four weeks by oral gavage. Both male and female mice ( $n=4$ per group) were tested. Results from the study (Figure 8) showed that intestinal polyp number was significantly reduced in both male and female mice treated with the Anthos ( $p=0.02$ and $p=0.004$, respectively). The average number of polyps for vehicle control animals was 41 polyps and with Anthos treatment it was 18 polyps. A slightly higher number of polyps was found in the female mice but reduction in the polyps with the Anthos treatment was evident, in fact, the effect was more pronounced ( 3.1 fold reduction, $p=0.004)$ compared to male mice ( 1.8 fold reduction, $p=0.02)$.

\section{Impact of Anthos treatment on colon tumor development in ETBF Apc ${ }^{\mathrm{Min} /+}$ mice CRC model}

Upon completion of in vitro testing of Anthos in both APC wild-type and APC mutant cell lines, the next step was to investigate whether Anthos treatment would impact colon tumor number in vivo in $\mathrm{Apc}^{\mathrm{Min} /+}$ mice which were treated with Anthos at either $20 \mathrm{mg} / \mathrm{kg}$ Anthos 5 times per week or $40 \mathrm{mg} / \mathrm{kg} 3$ times per week for 4 weeks by oral gavage. Results from the study (Figure 9) showed a significant reduction in the number of colon tumors with the Anthos treatment compared with the vehicle treatment $(p=0.03)$. The average number of tumors was reduced from 23 in control mice to 9 in Anthos-treated mice. Furthermore, similar average tumor counts were noted in both male and female animals $(p<0.05)$. These results support our in vitro findings. 

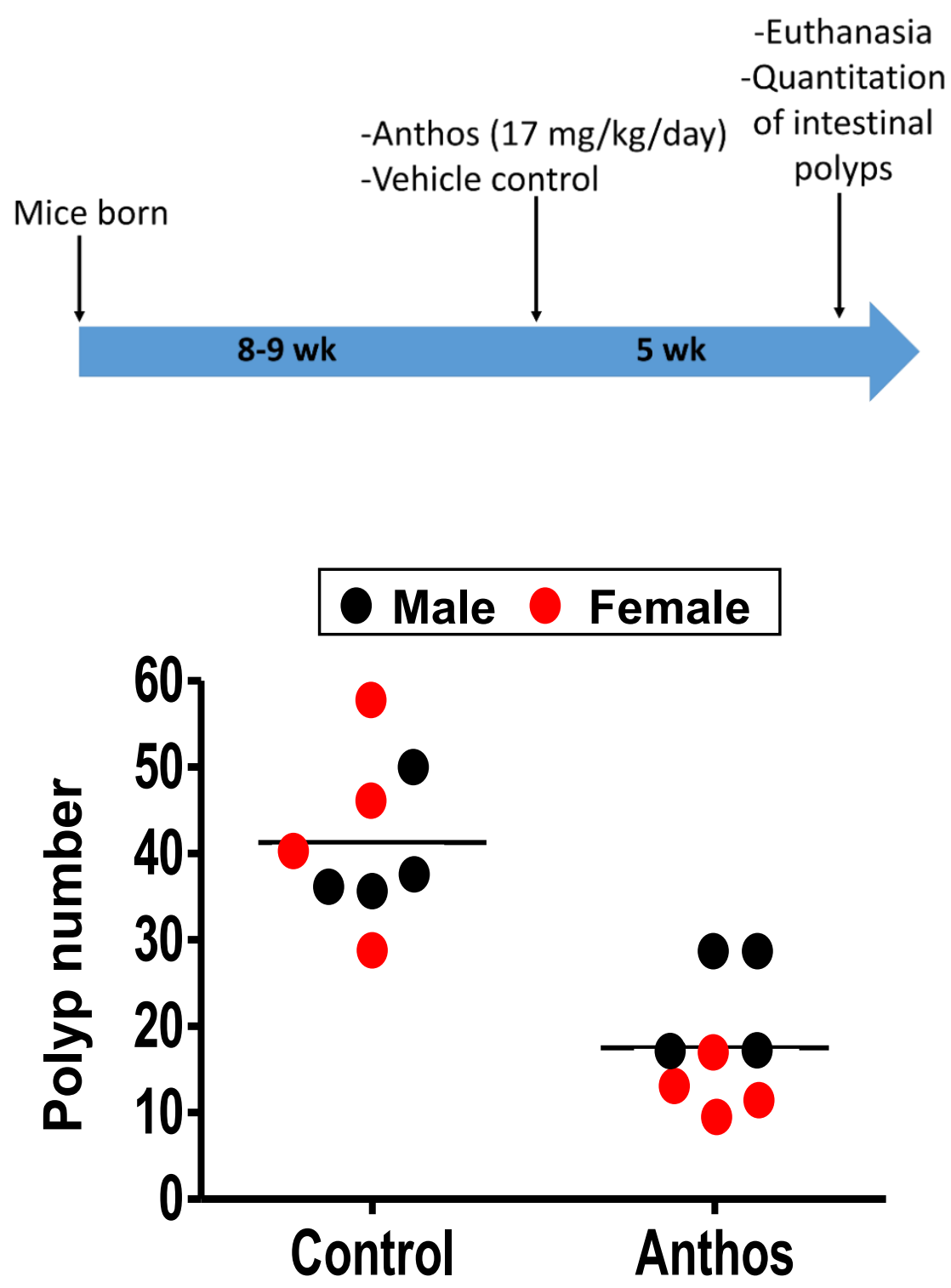

Figure 8 Antipolyp activity of bilberry-derived Anthos against intestinal polyps: $\mathrm{Apc}^{\mathrm{Min} /+}$ mice were treated via oral gavage with bilberry derived Anthos three times a week ( $40 \mathrm{mg} / \mathrm{kg} \mathrm{bw}$ ) or vehicle control. Data represent the distribution of animal polyp counts by gender, with the average noted. Male Anthos vs. control $p=0.02$ and female Anthos vs. control $p=0.004$. 


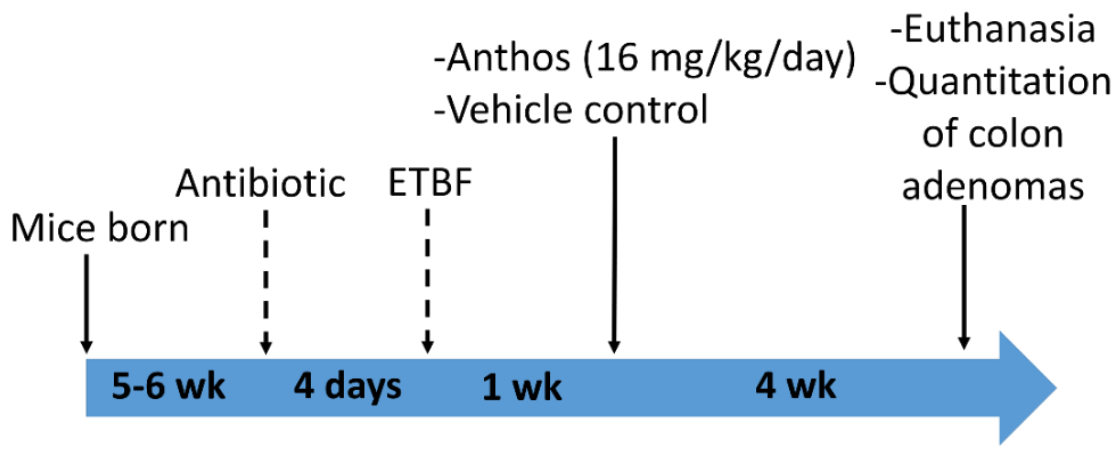

\section{- Male Female}

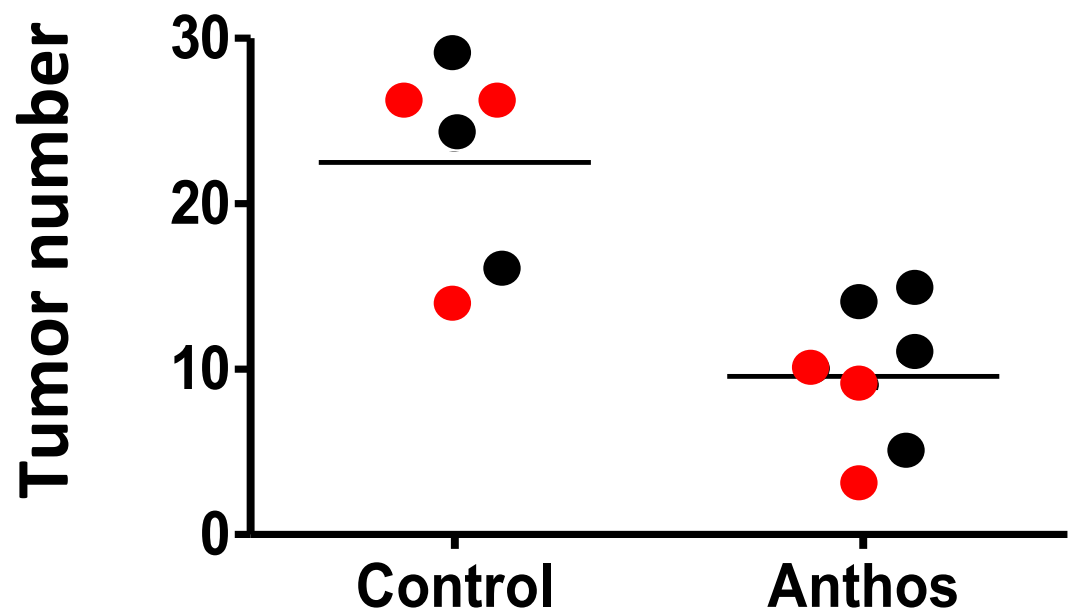

Figure 9 Anti-tumor activity of bilberry-derived Anthos against colon tumors: $\mathrm{Apc}^{\mathrm{Min} /+}$ mice were treated via oral gavage with bilberry derived Anthos three times per week (40 mg/kg bw), five times per week ( $20 \mathrm{mg} / \mathrm{kg} \mathrm{bw}$ ), or vehicle control. Data represent the distribution of animal tumor counts by gender, with the average noted. Male and female Anthos vs. control $p<0.05$. 


\section{Preliminary work investigating role of Anthos in the potential inhibition of EGFR and Src}

We next probed the mechanism of Anthos by western-blot analysis. Preliminary results comparing the phosphorylation of EGFR by probing for the phosphorylation of tyrosine 1048 (Y1048), to total EGFR, corrected for loading using $\beta$-actin suggest that Anthos led to a dose-dependent decrease in EGFR phosphorylation (Figure 10). A more pronounced decrease in phosphorylation was observed for Src at tyrosine 416 (Y416) (Figure 11). Minimal to no changes were seen in the expression of either total EGFR or total Src following Anthos treatment. These association studies will be used as the foundation for my mechanistic work which will be further elucidated with additional work to be completed in the near future.

\section{Loading and characterization of exosomes and ExoAnthos}

We investigated if a nano-formulation of Anthos would improve its potency. We chose the milk-derived exosomal nano formulation for Anthos (ExoAnthos) because of higher Anthos loading compared with the milk exosomes. An average practical drug loading of $25 \%$ was achieved for ExoAnthos. The average size for exosomes and ExoAnthos measured by the Zetasizer was $81 \mathrm{~nm}$ (Figure 12). Moreover, the surface morphology of ExoAnthos, determined by AFM, showed that ExoAnthos maintained the same characteristic spherical shape as the original exosomes.

\section{Profile of Anthos loading onto/into colostrum derived exosomes}

We next wanted to confirm that each of the five anthocyanidins, delphinidin, cyanidin, petunidin, peonidin, and malvidin present in the mixture were loaded proportionately onto/into the exosomes. We also wanted to confirm that the Anthos ratio was maintained during the storage. The HPLC profiles of the five Anthos contained in the free Anthos 
mixture (Figure 13) remained nearly the same as the native bilberry Anthos ratio for ExoAnthos on both day 0 and day 12 (Figure 13). Therefore, not only do the individual moieties of the Anthos mixture load equally, the ExoAnthos formulation was stable following freezing and thawing.

\section{Anti-proliferative effects of Exosomes alone on colon cancer cells}

Prior to assessing the impact of ExoAnthos, we first determined whether the exosomes per se (in the absence of Anthos) possessed anti-proliferative activity in the colon cancer cell lines, HCT-116 and HT-29 or normal CCD-18Co colon cells. Treatment of these colon cancer cell lines and normal cells with $0-200 \mu \mathrm{g} / \mathrm{ml}$ of exosomal proteins for $72 \mathrm{~h}$ resulted in minimal to modest cell growth inhibition (Figure 14). The APC wild-type cells, HCT-116 showed a maximum level of inhibition of $36 \%$ whereas normal CCD-18Co cells and the APC mutant cell line HT-29 showed only a slight cell kill (0 to 10\%). These results suggest that colostrum exosomes possess no in vitro toxicity to the normal cells and that they possess an intrinsic activity against colon cancer cells specifically. This "internal payload" effect is an exciting feature that our lab has also identified for other cancers such as breast and lung cancers [104].

\section{Anti-proliferative effects of bilberry Anthos versus ExoAnthos in normal colon and colon cancer cell lines}

We next compared the impact of exosomal formulation of the Anthos on the proliferation of the colon cancer cell lines HT-29, HCT-116, Caco2 and normal CCD-18Co colon cells. The results from these studies (Figure 15) showed a clear 

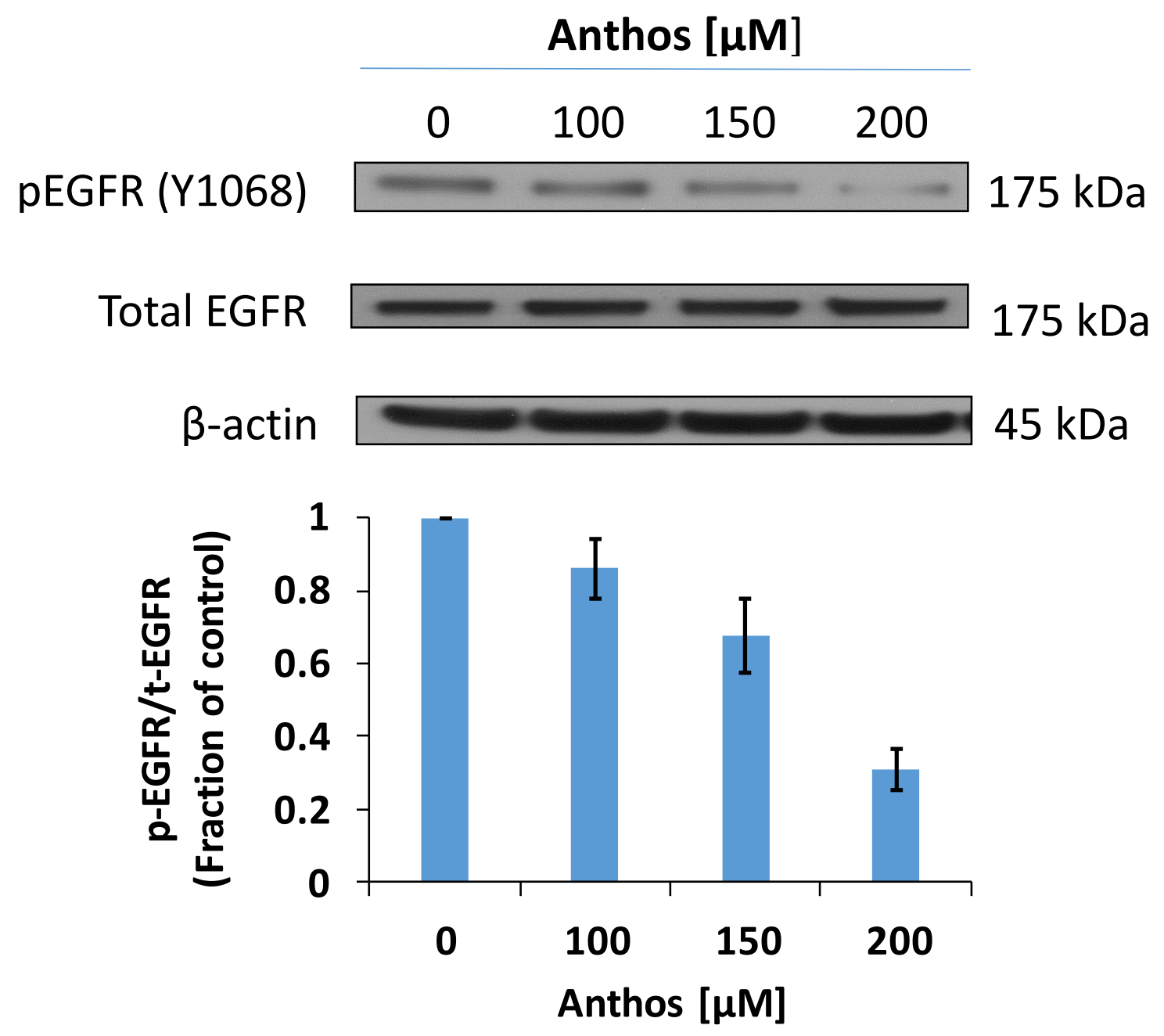

Figure 10 Changes in EGFR phosphorylation after treatment with Bilberry derived Anthos: Colon cancer cell line HT-29 was treated with various concentrations of bilberry-derived Anthos overnight and the effect on phosphorylation of EGFR at Y1068 was assessed using western blot analysis and compared to total EGFR and $\beta$-actin loading control. 


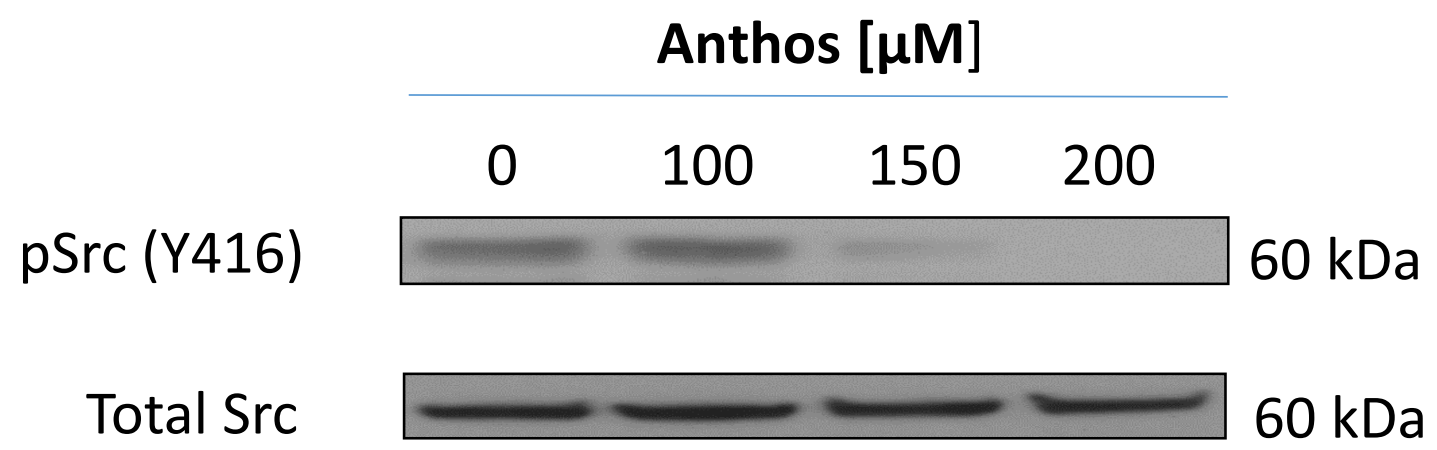

$\beta$-actin

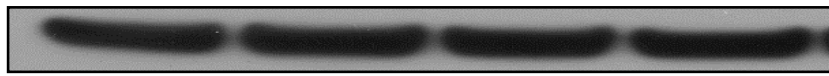

$45 \mathrm{kDa}$

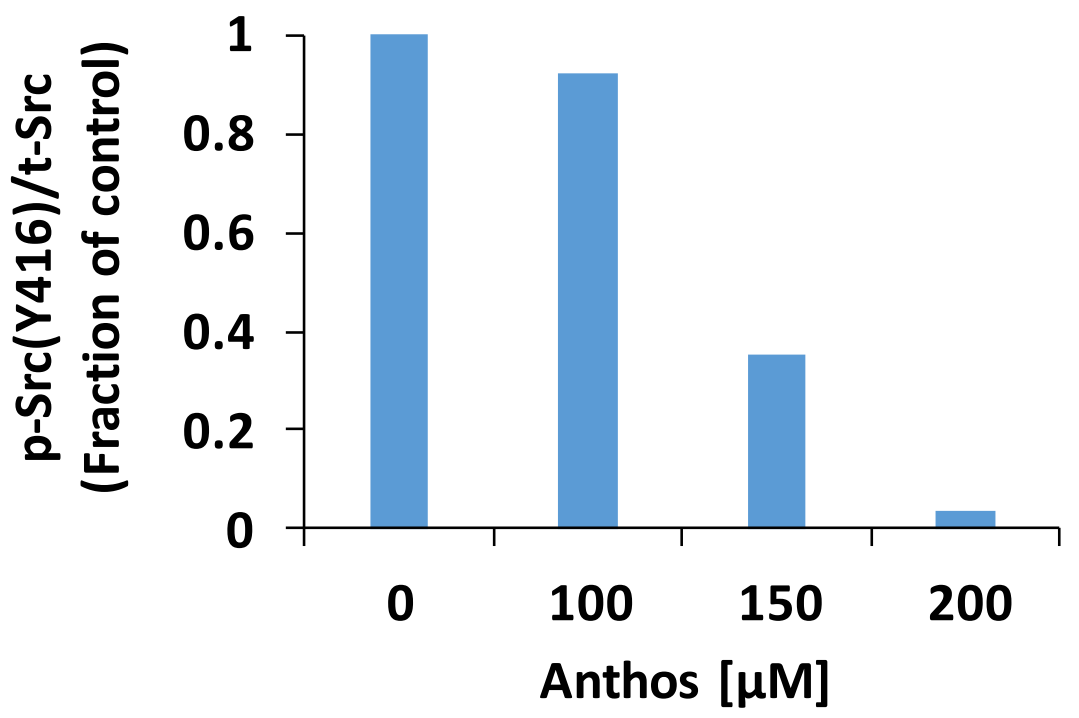

Figure 11 Changes in Src phosphorylation after treatment with Bilberry derived Anthos: Colon cancer cell line HT-29 was treated with various concentrations of bilberry-derived Anthos overnight and the effect on phosphorylation of Src at Y416 was assessed using western blot analysis and compared to total Src and $\beta$-actin loading control. 

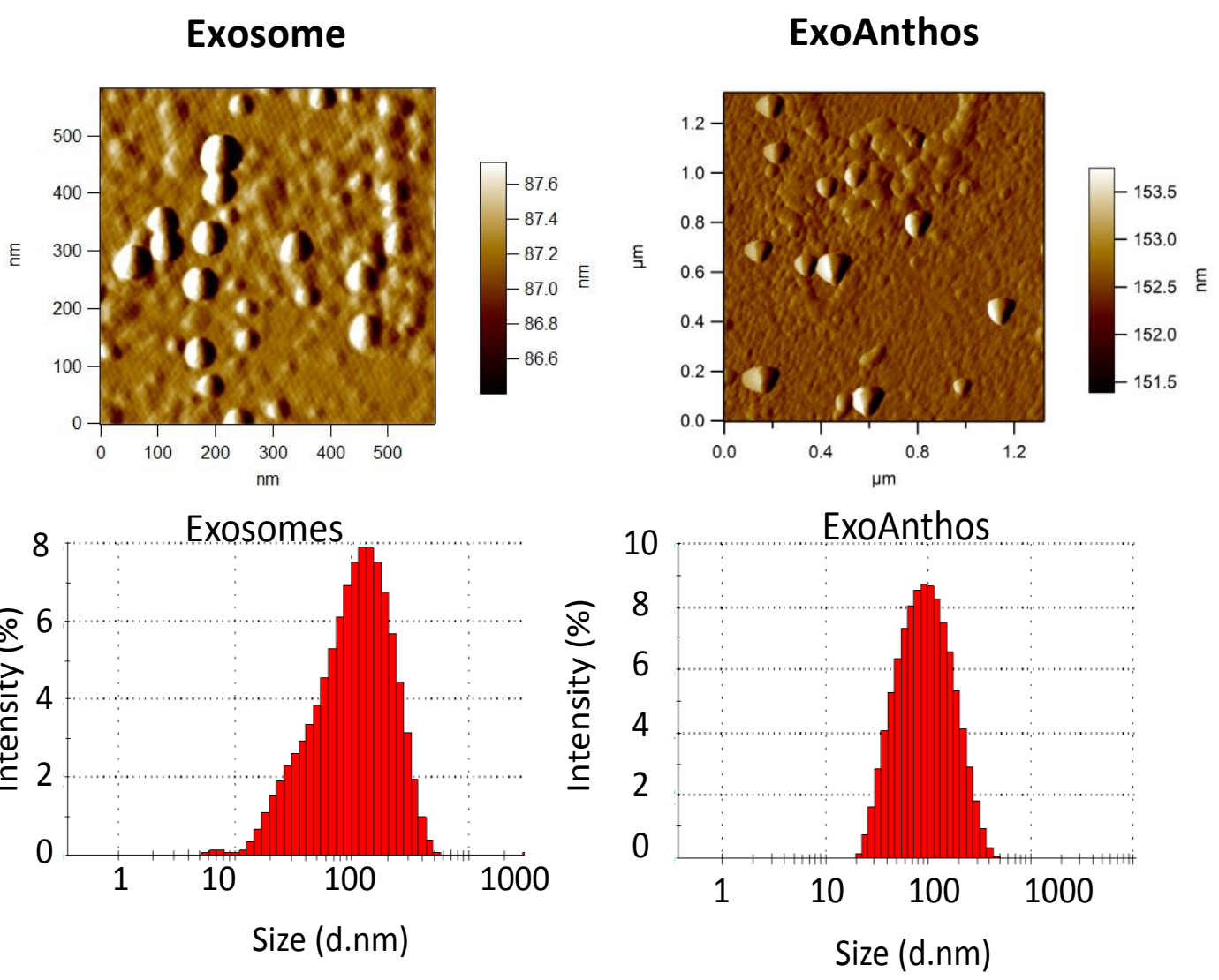

Figure 12 Morphology and size of milk exosomes and ExoAnthos: Exosomes derived from bovine milk and ExoAnthos were analyzed by AFM (A) and zetasizer (B). Amplitude and topographic images were captured simultaneously using a fixed force $<1 \mathrm{nM}$ and scanning rate of $1 \mathrm{~Hz}$. 

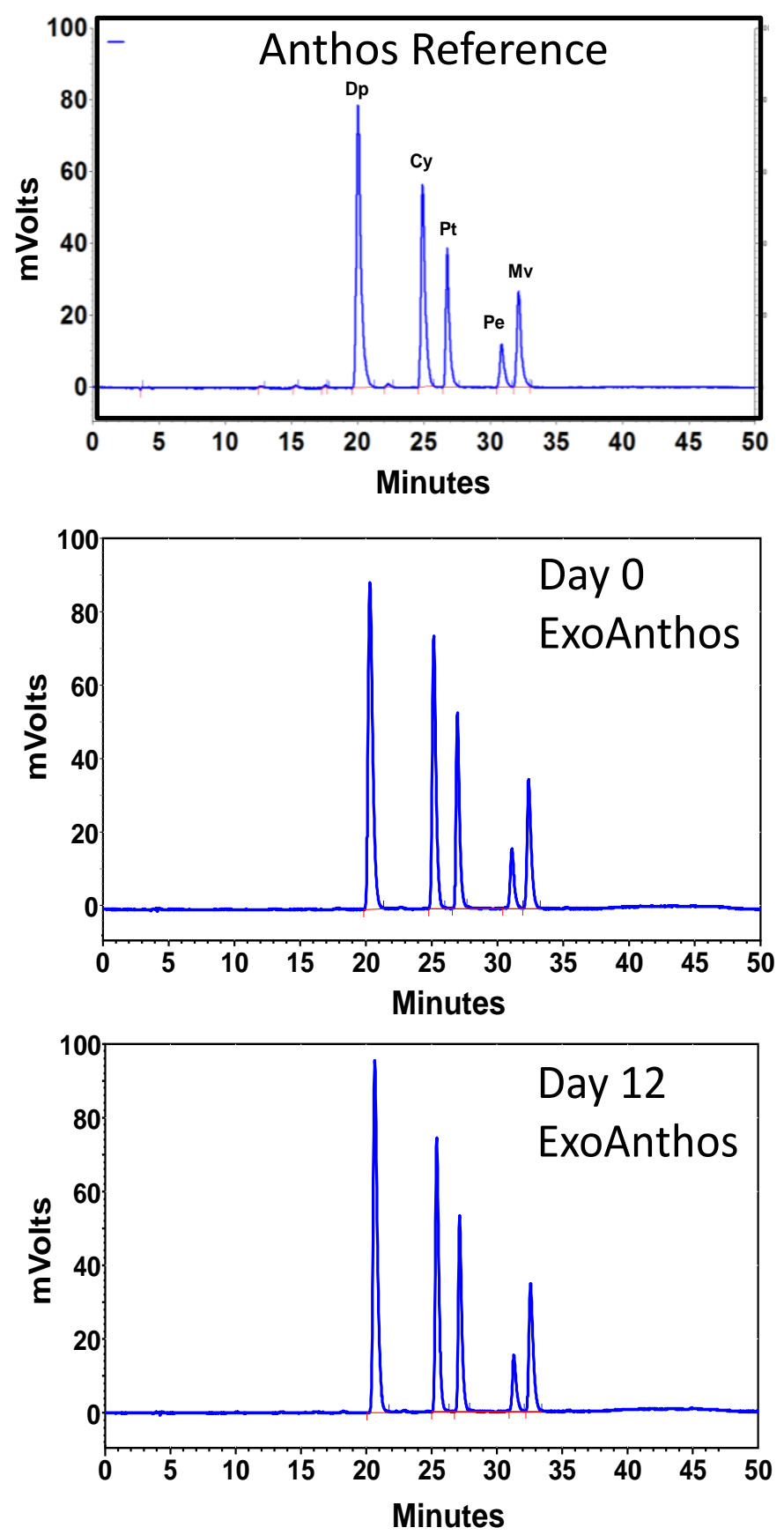

Figure 13 Loading and Stability of Anthos: HPLC profiles of Anthos extracted from exosomes day 0 and 12 days after loading compared to Anthos reference. 


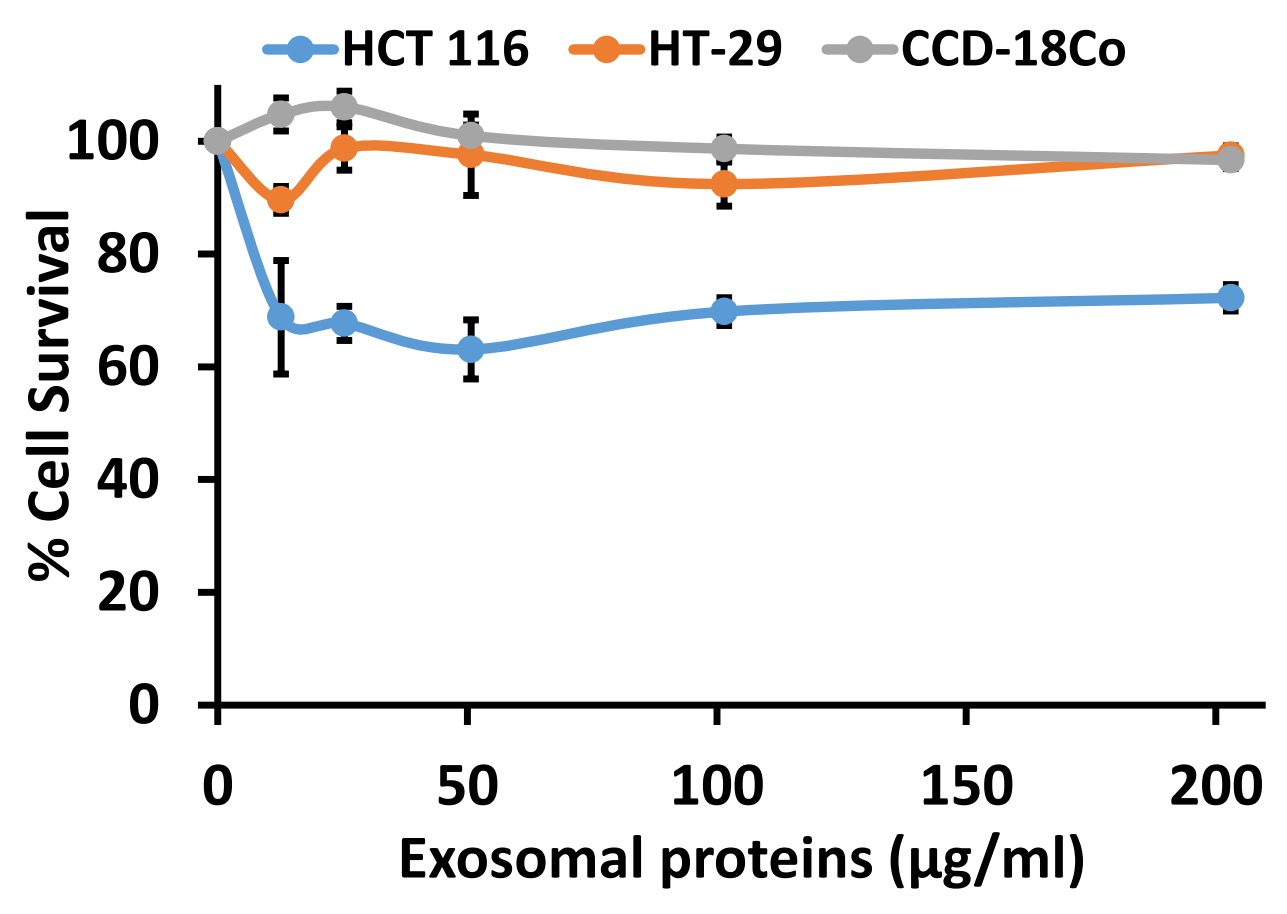

Figure 14 Antiproliferative activity of Exosomes against colon normal cells and cancer cell lines: Colon normal cells CCD-18Co and colon cancer cell lines HCT-116 and HT-29 were treated with various concentrations of milk derived exosomes for $72 \mathrm{~h}$ and the effect on cell growth inhibition was assessed using an MTT assay. Data represent average \pm SEM $(n=3)$. 


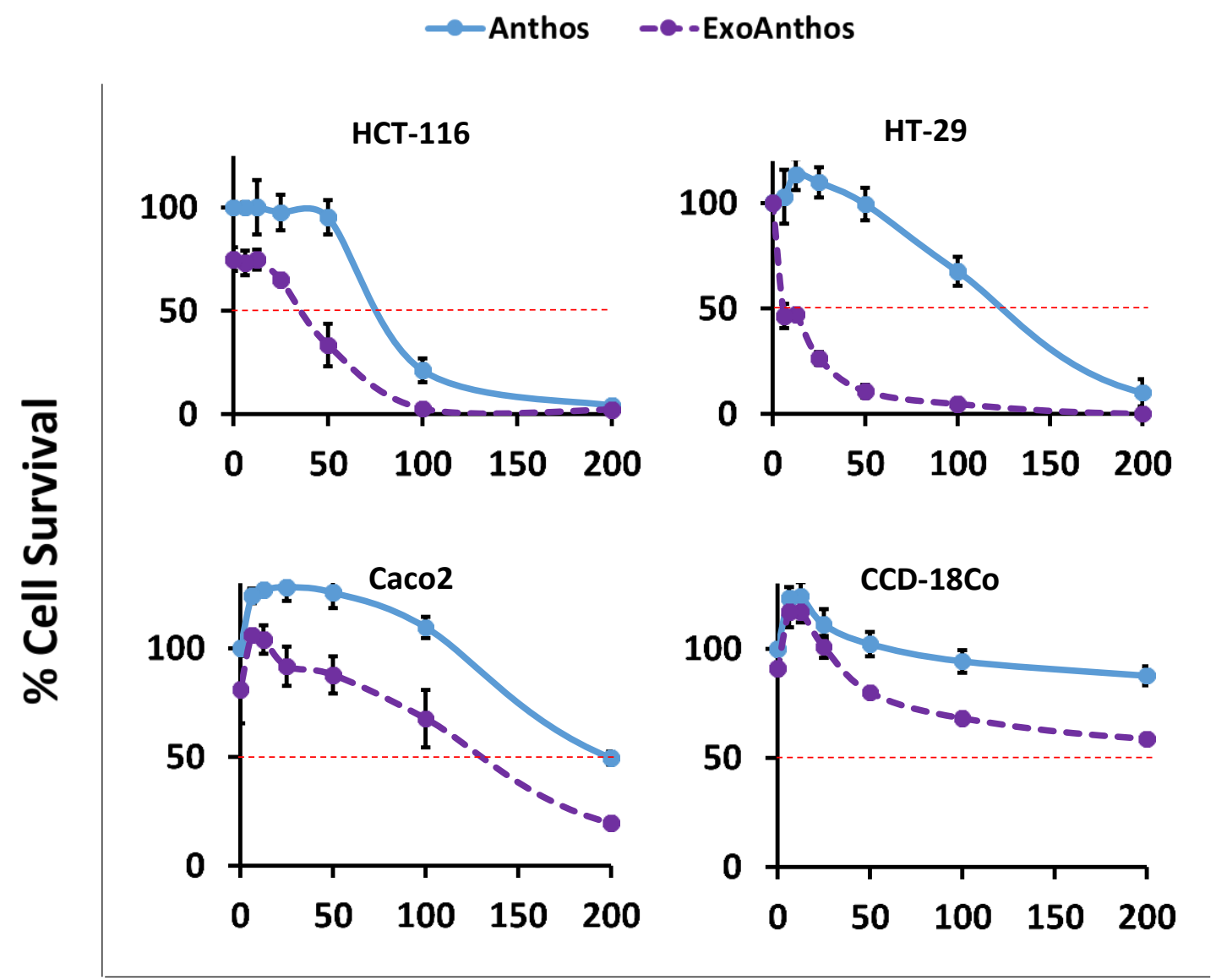

Anthos $[\mu \mathrm{M}]$

Figure 15 Antiproliferative activity of Anthos vs. ExoAnthos against colon normal cells and cancer cell lines: Colon normal cells CCD-18Co and colon cancer cell lines HCT-116, HT-29 and Caco 2 were treated with various concentrations of bilberry-derived Anthos and ExoAnthos for 72 $h$ and the effect on cell growth inhibition was assessed using an MTT assay. Data represent average $\pm \operatorname{SEM}(n=3)$. 


\begin{tabular}{|c|c|c|c|c|c|}
\hline Cell line & $\begin{array}{c}\text { IC } 5 \text { Anthos } \\
(\boldsymbol{\mu} \mathbf{M})\end{array}$ & SI Anthos & $\begin{array}{c}\text { IC50 ExoAnthos } \\
(\boldsymbol{\mu M})\end{array}$ & SI ExoAnthos & $\begin{array}{c}\text { Fold } \\
\text { difference in } \\
\text { IC }_{\mathbf{5 0}} \text { values }\end{array}$ \\
\hline CCD-18Co & 1050 & - & 407 & - & - \\
\hline HCT116 & 75 & 14 & 20 & 20 & 4 \\
\hline HT-29 & 124 & 9 & 8 & 51 & 16 \\
\hline
\end{tabular}

TABLE 2: Antiproliferative activity and selectivity index for bilberry derived Anthos and ExoAnthos against colon cancer and normal colon cells 
increase in the anti-proliferative properties of Anthos against colon cancer cells, with 416-fold decreases in the $\mathrm{IC}_{50}$ values of ExoAnthos as compared to the free Anthos (Table 2). One can posit that the improved anti-proliferative effects of the ExoAnthos formulation over Anthos alone is most likely due to the increased cell uptake and stability in media of the ExoAnthos over Anthos. Part of the higher potency of ExoAnthos may be attributed to the intrinsic effect of the exosomes alone.

In order to determine whether Anthos or ExoAnthos were selective toward colon cancer over normal colon cells in vitro, we determined the selectivity index (SI) values for both HCT 116 and HT-29 colon cancer cells compared to normal colon CCD-18Co cells. The results (Table 2) showed not only that both Anthos and ExoAnthos were selective for colon cancer over normal colon cells, but that ExoAnthos enhanced this selectivity, with the greatest increase yielded in HT-29 cells which went from an SI value of 9 for Anthos to 51 for ExoAnthos. Overall, these results confirm that Anthos and ExoAnthos do not show in vitro toxicity for the normal CCD-18Co colon cells and that the cytotoxicity is specific for colon cancer cells.

Impact of Milk-derived ExoAnthos vs. Colostrum-derived ExoAnthos on the Antiproliferative effects in colon cancer cells

The next generation of exosomes that 3P Biotechnologies has been developing are derived from bovine colostrum. Prior to this work, no in vitro or in vivo data had been collected comparing the milk exosomes loaded with Anthos versus the colostrum exosomes loaded with Anthos. To compare the two formulations, we assessed the antiproliferative activity of the milk- and the colostrum-derived ExoAnthos formulations alongside the free Anthos in the colon cancer cell line HCT-116. The results from these 
studies (Figure 16) confirmed that no difference in the anti-proliferative properties exists between colostrum ExoAnthos and milk ExoAnthos formulations for HCT-116 colon cancer cells. Both formulations showed a clear increase in the anti-proliferative properties of ExoAnthos over the free Anthos against colon cancer cells. With 4-fold decreases in the $\mathrm{IC}_{50}$ values of Anthos, when delivered by either colostrum- or milk-derived exosomes. 


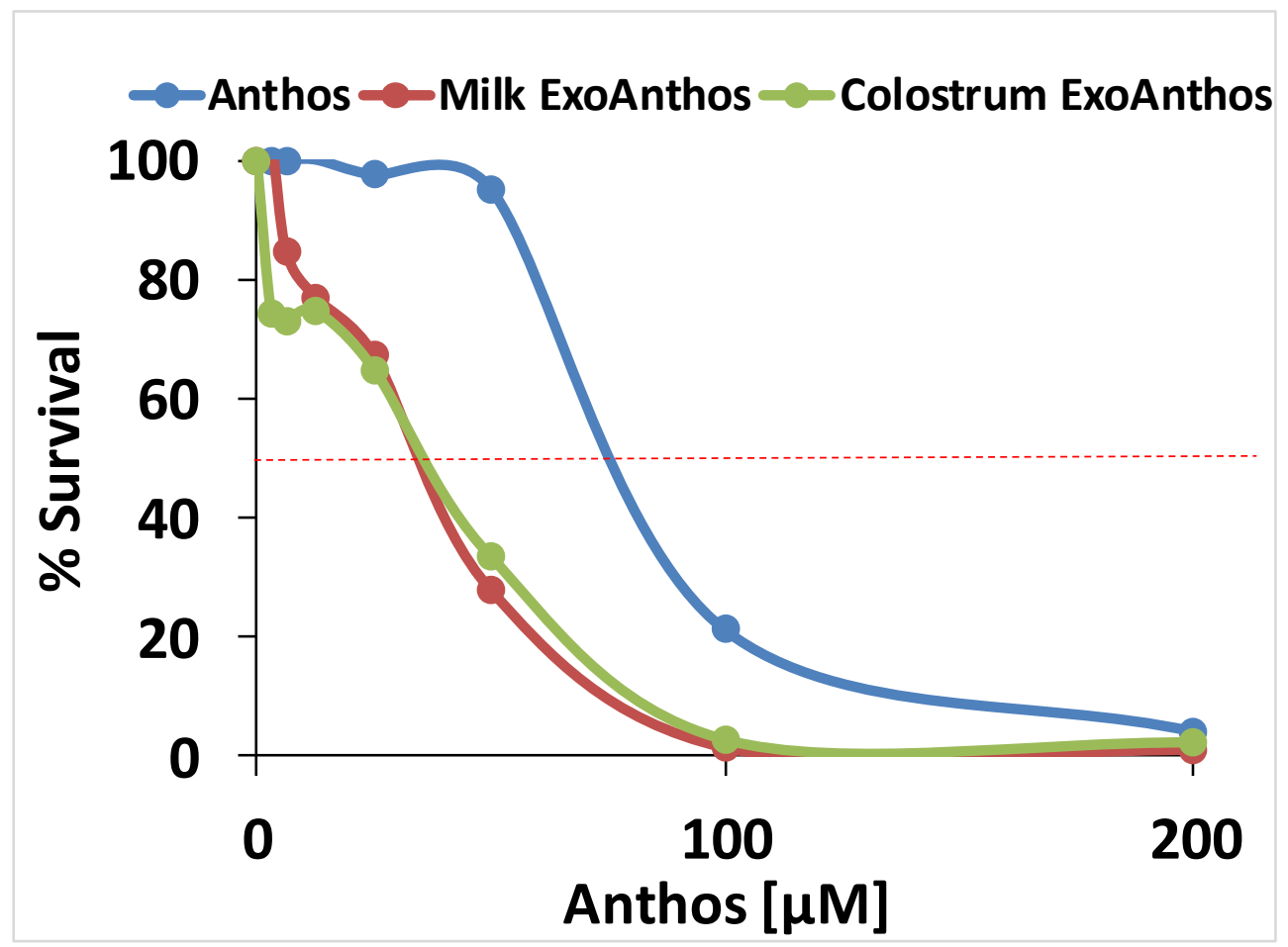

Figure 16 Antiproliferative activity of Anthos vs. Milk ExoAnthos and Colostrum ExoAnthos against colon cancer cell line HCT-116: Colon cancer cell line HCT116 was treated with various concentrations of bilberry-derived Anthos, milk ExoAnthos and colostrum ExoAnthos for $72 \mathrm{~h}$ and the effect on cell growth inhibition was assessed using an MTT assay. 


\section{DISCUSSION}

Although great progress has been made in the treatment of $\mathrm{CRC}$, it still remains the third leading cause of cancer related death. Additionally, FAP remains an orphan disease with the only approved treatment being surgical resection of the colon. Furthermore, even after surgical resection, individuals with FAP still face the risk of developing cancers of the small intestine. Therefore, there is an urgent need for developing novel treatments to combat both $\mathrm{CRC}$ as well as FAP.

The plant pigments known as anthocyanins have been consumed by humans throughout history. Within recent history anthocyanins have become an area of interest for their potential benefits to human health. Although benefits have been noted for anthocyanins, limitations have also become apparent due to their limited bioavailability and stability. Previous work from our lab has shown that Anthos are more potent than anthocyanins in inhibiting non-small-cell lung cancer cell growth [58, 96]. Additionally, work from our lab also has shown that both dietary black raspberry and blueberry caused significant inhibition of breast cancer in a rat model [105] and lung cancer in a mouse model [106]. However, prior to these studies no work had been conducted to test the impact of Anthos on CRC or FAP. Therefore, for my Master's project, after working on Anthos and ExoAnthos in breast cancer initially, I have focused my research to investigate the impact of Anthos and ExoAnthos on colorectal cancer and FAP, the results of which are contained within this thesis.

Previous studies in our lab have shown that differences exist in the antiproliferative capacity of Anthos versus anthocyanins in lung cancer [96]. Results from the comparison 
of Anthos with their respective anthocyanins show that delphinidin, and cyanidin are more potent that their 3-monoglucoside and 3,5-diglucoside anthocyanin counterparts in the colon cancer cell line HCT-116. These results are not surprising considering that Anthos not only are somewhat more lipophilic due to their higher partition coefficients than their anthocyanin counterparts and are therefore able to be taken up passively by cells whereas anthocyanins are known to require active transport.

Interestingly, when the colon cancer cell lines, HCT-116 and HT-29 were treated with individual Anthos, including delphinidin, cyanidin, malvidin, or petunidin, different levels of antiproliferative properties were noted for each compound. Furthermore, although delphinidin and petunidin yielded the lowest $\mathrm{IC}_{50}$ values, slightly different trends were noted for the remaining Anthos in each cell line. Moreover, slightly lower $\mathrm{IC}_{50}$ values were achieved by HCT-116 cells when compared to HT-29 cells. Structure-function relationship differences have been suggested to exist previously. For instance, it was noted that delphinidin and cyanidin inhibited LPS-induced COX-2 expression, whereas malvidin, peonidin and pelargonidin did not show a similar trend [107]. Additionally, different Anthos substitution patterns were found to lead to different cellular signaling cascades effects [108]. For instance, only malvidin which features methoxy groups at the 3 ' and 5' positions of the B-ring lead to inhibition of cAMP-specific phosphodiesterases (PDEs) whereas, cyanidin and delphinidin were shown to inhibit EGFR in human vulva carcinoma A431 cells [108]. However, it should be noted that the authors of this study did not investigate petunidin, which showed the second highest antiproliferative impact, after delphinidin, in our studies with HT-29 and HCT-116 colon cancer cells. Therefore, more work is still needed to uncover differences in mechanisms, which may exist between individual Anthos and whether alternative mixtures may provide an additional synergistic value over the native bilberry mixture. 
In addition to the trends noted for the individual Anthos, HCT-116 cells also appeared to be more sensitive to the native mixture of the Anthos from bilberries when compared to HT-29 cells. This difference between the two cell lines is perhaps due to the influence of Anthos on p53, which is active in HCT-116 but mutated in HT-29 cells. It has been previously reported that anthocyanins alter the expression of p53 [109]. Given the preliminary findings showing decreased activity of EGFR and Src one could postulate that this could lead to decreased STAT3 activity thereby resulting in changes in the expression of factors such as p53 along with a host of other key players in carcinogenesis such as cMyc, Bcl-2, Bcl-xL, survivin, Cyclin D1 among many others [110-114]. This is due to the ability of STAT3 to act both directly and indirectly due to its ability to mediate the expression of or physically associate with other transcription factors thereby suppressing or enhancing gene regulatory functions [115]. Additional mechanistic studies are planned to clearly elucidate the specifics of the pathway(s). We also plan to examine the effects of the individual Anthos and the optimized Anthos mixture for their relative effects on the EGFR and Src activities.

Individuals with FAP characteristically develop hundreds to thousands of polyps in their intestines. Typically by their late teens to early twenties, FAP patients undergo CRC prophylactic surgery. Given the lack of treatment options for FAP, developing alternative preventative treatment options clearly represents an "unmet" need. With this in mind, the potential application of Anthos to the prevention of FAP is a key possibility following the successful in vitro results with the colon cancer cell lines HT-29, HCT-116 and Caco-2. In vivo studies assessing the impact that Anthos has on FAP in $\mathrm{Apc}^{\mathrm{Min} /+}$ mouse model showed significant decreases in intestinal polyp number in the Anthos-treated mice compared to vehicle treatment in both male and females $(p=0.02$ and $p=0.004$ respectively). Interestingly, it was previously shown that APC deficiency was associated 
with an increase in EGFR activity and c-Src expression in $\mathrm{Apc}^{\mathrm{Min} /+}$ mouse adenomas and intestinal enterocytes [116]. In light of the preliminary in vitro findings with Anthos decreasing the activity of EGFR and c-Src, we postulate that Anthos is decreasing polyp formation via this pathway. Further studies will be undertaken to better study the true nature of the relationship between Anthos and receptor and non-receptor tyrosine kinases using the $\mathrm{Apc}^{\mathrm{Min} /+}$ model for FAP. Therefore, given the significant decrease in polyps observed and the mechanistic implications, the potential for Anthos treatment for FAP patients appears promising.

In addition to the promising results attained with the chemoprevention and FAP study in the $\mathrm{Apc}^{\mathrm{Min} /+}$ mouse model, additional in vivo work assessing the impact of Anthos on a CRC Apc ${ }^{\mathrm{Min} /+}$ ETBF mouse model showed that Anthos treatment significantly $(p<0.05)$ lowered the number of colorectal tumors in the Anthos-treated mice compared to vehicle treatment. These results corroborate with the in vitro data. ETBF, a subtype of B. fragilis that secrets the metalloprotease enterotoxin B. Fragilis toxin (BFT), is associated with diarrheal disease in both humans and animals as well as active inflammatory bowel disease. A study looking at the prevalence of ETBF found that $26.8 \%$ of individuals with diarrhea and $12.4 \%$ of individuals without diarrhea had stool samples that were positive for the presence of ETBF [99]. In addition to increasing the secretion of chloride and permeability of intestinal epithelial cells, BFT also activates STAT3 and TH17 responses and leads to increased Cox-2. Given the preliminary in vitro data which suggests that Anthos decreases the activity of EGFR and Src, one could posit that Anthos treatment may act by effectively decreasing the activity of STAT3 and ultimately altering downstream expression of Cox-2, c-myc etc. Additional in vitro and in vivo studies will be conducted to further elucidate this pathway. Overall, results from in vivo work with an $\mathrm{Apc}^{\mathrm{Min} /+}$ mouse model for FAP offer an exciting possibility for potential treatments in the future. 
Benefits of exosomal delivery have been established within our lab for drugs such as withaferin A, celestrol and paclitaxel in lung cancer $[96,97]$. One of the key goals of my graduate research project is to utilize exosomal delivery for Anthos. The average drug load attained for the ExoAnthos is $25 \%$. Using HPLC-PDA-UV it has also been found that all the individual Anthos were loaded proportionately. Furthermore, loading of the Anthos onto/into the exosomes did not significantly change their size or morphology. When comparing the impact that exosomal delivery of the Anthos has on colon cancer cell proliferation using the APC mutant and APC wild-type colon cancer cell lines, 16-fold and 4-fold reductions in the $\mathrm{IC}_{50}$ values were found in the respective HT-29 and HCT-116 cells. These results correspond with our previous findings for other drugs delivered using exosomes [104]. Therefore, the results support our initial hypothesis that exosomal delivery will improve Anthos potency presumably due to increased bioavailability and stability of Anthos.

Bovine milk-derived exosomes have been well established as a nano drug carrier within the Gupta lab [95, 96]. Before switching from bovine milk to bovine colostrum derived exosomes within the study, the new system was investigated and compared to Anthosloaded milk exosomes. Results from the comparison of milk- versus colostrum-derived exosomes loaded with Anthos showed that the colostrum exosomes resulted in higher Anthos loading, although no significant differences were found in the anti-proliferative activity of the two formulations. Therefore, once this was established, my future work will utilize the colostrum-derived exosomes. 


\section{SUMMARY \& CONCLUSIONS}

The findings from these series of studies establish the therapeutic potential of Anthos on both $\mathrm{CRC}$ and FAP. In addition to confirming previous findings by our lab that Anthos are more potent than anthocyanins, the results from in vitro work testing of the individual Anthos also illustrate the different potencies of specific Anthos such as delphinidin and petunidin over malvidin and peonidin. Our findings from the in vitro studies also suggest that great promise exists for ExoAnthos in further enhancing Anthos effects. Preliminary mechanistic work suggested that Anthos resulted in dose-dependent decrease in the phosphorylation of Src (Y418) and EGFR (Y1068) which could potentially serve as one of the pathways by which Anthos may be decreasing cell proliferation.

Current limitations of this work include the lack of an in vivo dose-escalation study. Additionally, further studies need to be completed to more definitively elucidate the nature of the interaction between Anthos, EGFR, and Src and the downstream targets such as pSTAT5b, total pSTAT5b, pSTAT3, total STAT3, Cox-2, c-myc, Cyclin D1 and D2, $\beta$ catenin et cetera. Future work will also focus on identifying an optimal mixture of Anthos, followed by the generation of an exosomal formulation featuring this specific mixture. One of the key limitations of using the ExoAnthos formulation is with low drug load. Therefore, future work will also investigate the kinetic parameters to increase the Anthos loading onto/into the exosomes. An additional area that will be investigated is the impact that Anthos and ExoAnthos have on immunological markers including, but not limited to IL-1 $\beta$, IL-4, IL-6, IL-10, IL-17, IFNy and TNFa. Furthermore, my PhD. work will investigate the 
impact of Anthos on a proposed dialogue between the environmental carcinogen

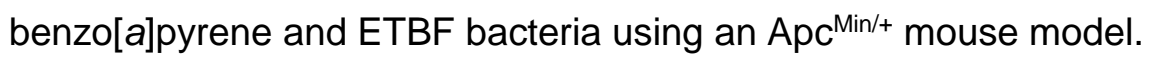




\section{REFERENCES}

[1] G. Murphy, S.S. Devesa, A.J. Cross, P.D. Inskip, K.A. McGlynn, M.B. Cook, Sex Disparities in Colorectal Cancer Incidence by Anatomic Subsite, Race and Age, International journal of cancer. Journal international du cancer, 128 (2011) 1668-1675.

[2] N. Shivappa, A. Zucchetto, M. Montella, D. Serraino, S.E. Steck, C. La Vecchia, J.R. Hebert, Inflammatory potential of diet and risk of colorectal cancer: a case-control study from Italy, The British journal of nutrition, 114 (2015) 152-158.

[3] A. Jemal, F. Bray, M.M. Center, J. Ferlay, E. Ward, D. Forman, Global cancer statistics, CA: a cancer journal for clinicians, 61 (2011) 69-90.

[4] R.L. Siegel, S.A. Fedewa, W.F. Anderson, K.D. Miller, J. Ma, P.S. Rosenberg, A. Jemal, Colorectal Cancer Incidence Patterns in the United States, 1974-2013, Journal of the National Cancer Institute, 109 (2017).

[5] J. Terzić, S. Grivennikov, E. Karin, M. Karin, Inflammation and Colon Cancer, Gastroenterology, 138 (2010) 2101-2114.e2105.

[6] S.L. Schmit, H.S. Rennert, G. Rennert, S.B. Gruber, Coffee Consumption and the Risk of Colorectal Cancer, Cancer epidemiology, biomarkers \& prevention : a publication of the American Association for Cancer Research, cosponsored by the American Society of Preventive Oncology, 25 (2016) 634-639.

[7] G. Yang, W. Zheng, Y.B. Xiang, J. Gao, H.L. Li, X. Zhang, Y.T. Gao, X.O. Shu, Green tea consumption and colorectal cancer risk: a report from the Shanghai Men's Health Study, Carcinogenesis, 32 (2011) 1684-1688.

[8] J.N. Poynter , S.B. Gruber , P.D.R. Higgins , R. Almog , J.D. Bonner , H.S. Rennert , M. Low , J.K. Greenson, G. Rennert Statins and the Risk of Colorectal Cancer, New England Journal of Medicine, 352 (2005) 2184-2192.

[9] L.A. Garcia-Rodriguez, C. Huerta-Alvarez, Reduced risk of colorectal cancer among long-term users of aspirin and nonaspirin nonsteroidal antiinflammatory drugs, Epidemiology (Cambridge, Mass.), 12 (2001) 88-93.

[10] Y. Imamura, T. Morikawa, X. Liao, P. Lochhead, A. Kuchiba, M. Yamauchi, Z.R. Qian, R. Nishihara, J.A. Meyerhardt, K.M. Haigis, C.S. Fuchs, S. Ogino, Specific mutations in KRAS codons 12 and 13, and patient prognosis in 1075 BRAF wild-type colorectal cancers, Clinical cancer research : an official journal of the American Association for Cancer Research, 18 (2012) 4753-4763. 
[11] W. Li, T. Qiu, Y. Ling, L. Guo, L. Li, J. Ying, Molecular pathological epidemiology of colorectal cancer in Chinese patients with KRAS and BRAF mutations, Oncotarget, 6 (2015) 39607-39613.

[12] C.E. Atreya, Z. Sangale, N. Xu, M.R. Matli, E. Tikishvili, W. Welbourn, S. Stone, K.M. Shokat, R.S. Warren, PTEN expression is consistent in colorectal cancer primaries and metastases and associates with patient survival, Cancer medicine, 2 (2013) 496506.

[13] Y. Chen, Y. Shi, J. Lin, Y.B. Ye, X.J. Wang, G. Chen, Z.Q. Guo, Combined Analysis of EGFR and PTEN Status in Patients With KRAS Wild-Type Metastatic Colorectal Cancer, Medicine, 94 (2015) e1698.

[14] M. Han, G. Wu, P. Sun, J. Nie, J. Zhang, Y. Li, Association of genetic polymorphisms in PTEN and additional interaction with alcohol consumption and smoking on colorectal cancer in Chinese population, International Journal of Clinical and Experimental Medicine, 8 (2015) 21629-21634.

[15] J.L. Boulay, G. Mild, A. Lowy, J. Reuter, M. Lagrange, L. Terracciano, U. Laffer, R. Herrmann, C. Rochlitz, SMAD7 is a prognostic marker in patients with colorectal cancer, International journal of cancer, 104 (2003) 446-449.

[16] A.J. Levine, A.I. Phipps, J.A. Baron, D.D. Buchanan, D.J. Ahnen, S.A. Cohen, N.M. Lindor, P.A. Newcomb, C. Rosty, R.W. Haile, P.W. Laird, D.J. Weisenberger, Clinicopathologic Risk Factor Distributions for MLH1 Promoter Region Methylation in CIMP-Positive Tumors, Cancer epidemiology, biomarkers \& prevention : a publication of the American Association for Cancer Research, cosponsored by the American Society of Preventive Oncology, 25 (2016) 68-75.

[17] S.P. Cleary, M. Cotterchio, M.A. Jenkins, H. Kim, R. Bristow, R. Green, R. Haile, J.L. Hopper, L. LeMarchand, N. Lindor, P. Parfrey, J. Potter, B. Younghusband, S. Gallinger, Germline MutY human homologue mutations and colorectal cancer: a multisite case-control study, Gastroenterology, 136 (2009) 1251-1260.

[18] M. Lüchtenborg, M.P. Weijenberg, G.M.J.M. Roemen, A.P. de Bruïne, P.A. van den Brandt, M.H.F.M. Lentjes, M. Brink, M. van Engeland, R.A. Goldbohm, A.F.P.M. de Goeij, APC mutations in sporadic colorectal carcinomas from The Netherlands Cohort Study, Carcinogenesis, 25 (2004) 1219-1226.

[19] M.A. Hildebrandt, M.E. Reyes, M. Lin, Y. He, S.V. Nguyen, E.T. Hawk, X. Wu, Germline Genetic Variants in the Wnt/beta-Catenin Pathway as Predictors of Colorectal Cancer Risk, Cancer epidemiology, biomarkers \& prevention : a publication of the American Association for Cancer Research, cosponsored by the American Society of Preventive Oncology, 25 (2016) 540-546.

[20] R.N. Jorissen, M. Christie, D. Mouradov, A. Sakthianandeswaren, S. Li, C. Love, Z.Z. $\mathrm{Xu}$, P.L. Molloy, I.T. Jones, S. McLaughlin, R.L. Ward, N.J. Hawkins, A.R. Ruszkiewicz, J. Moore, A.W. Burgess, D. Busam, Q. Zhao, R.L. Strausberg, L. Lipton, J. Desai, P. Gibbs, O.M. Sieber, Wild-type APC predicts poor prognosis in 
microsatellite-stable proximal colon cancer, British journal of cancer, 113 (2015) 979988.

[21] W.S. Samowitz, M.L. Slattery, C. Sweeney, J. Herrick, R.K. Wolff, H. Albertsen, APC mutations and other genetic and epigenetic changes in colon cancer, Molecular cancer research : MCR, 5 (2007) 165-170.

[22] M.S. Pino, D.C. Chung, The chromosomal instability pathway in colon cancer, Gastroenterology, 138 (2010) 2059-2072.

[23] E.R. Fearon, B. Vogelstein, A genetic model for colorectal tumorigenesis, Cell, 61 (1990) 759-767.

[24] S. Markowitz, J. Wang, L. Myeroff, R. Parsons, L. Sun, J. Lutterbaugh, R.S. Fan, E. Zborowska, K.W. Kinzler, B. Vogelstein, et al., Inactivation of the type II TGF-beta receptor in colon cancer cells with microsatellite instability, Science (New York, N.Y.), 268 (1995) 1336-1338.

[25] Y. Samuels, V.E. Velculescu, Oncogenic mutations of PIK3CA in human cancers, Cell cycle (Georgetown, Tex.), 3 (2004) 1221-1224.

[26] S.J. Baker, E.R. Fearon, J.M. Nigro, S.R. Hamilton, A.C. Preisinger, J.M. Jessup, P. vanTuinen, D.H. Ledbetter, D.F. Barker, Y. Nakamura, R. White, B. Vogelstein, Chromosome 17 deletions and p53 gene mutations in colorectal carcinomas, Science (New York, N.Y.), 244 (1989) 217-221.

[27] K.M. Haigis, K.R. Kendall, Y. Wang, A. Cheung, M.C. Haigis, J.N. Glickman, M. NiwaKawakita, A. Sweet-Cordero, J. Sebolt-Leopold, K.M. Shannon, J. Settleman, M. Giovannini, T. Jacks, Differential effects of oncogenic K-Ras and N-Ras on proliferation, differentiation and tumor progression in the colon, Nature genetics, 40 (2008) 600-608.

[28] J.N. Poynter, K.D. Siegmund, D.J. Weisenberger, T.I. Long, S.N. Thibodeau, N. Lindor, J. Young, M.A. Jenkins, J.L. Hopper, J.A. Baron, D. Buchanan, G. Casey, A.J. Levine, L.L. Marchand, S. Gallinger, B. Bapat, J.D. Potter, P.A. Newcomb, R.W. Haile, t.C.C.F.R.I. Laird, W. Peter, Molecular characterization of MSI-H colorectal cancer by $\mathrm{MLHI}$ promoter methylation, immunohistochemistry and mismatch repair germline mutation screening, Cancer epidemiology, biomarkers \& prevention : a publication of the American Association for Cancer Research, cosponsored by the American Society of Preventive Oncology, 17 (2008) 3208-3215.

[29] C.R. Boland, A. Goel, Microsatellite Instability in Colorectal Cancer, Gastroenterology, 138 (2010) 2073-2087.e2073.

[30] C.C. Pritchard, W.M. Grady, Colorectal cancer molecular biology moves into clinical practice, Gut, (2010).

[31] C.H. Kim, J.W. Huh, H.R. Kim, Y.J. Kim, CpG island methylator phenotype is an independent predictor of survival after curative resection for colorectal cancer: A prospective cohort study, J Gastroenterol Hepatol, (2017). 
[32] D.L. Worthley, B.A. Leggett, Colorectal cancer: molecular features and clinical opportunities, The Clinical biochemist. Reviews / Australian Association of Clinical Biochemists, 31 (2010) 31-38.

[33] S.D. Markowitz, M.M. Bertagnolli, Molecular origins of cancer: Molecular basis of colorectal cancer, The New England journal of medicine, 361 (2009) 2449-2460.

[34] S. Ogino, A. Goel, Molecular classification and correlates in colorectal cancer, The Journal of molecular diagnostics : JMD, 10 (2008) 13-27.

[35] J.R. Jass, Classification of colorectal cancer based on correlation of clinical, morphological and molecular features, Histopathology, 50 (2007) 113-130.

[36] C.G. Moertel, T.R. Fleming, J.S. Macdonald, D.G. Haller, J.A. Laurie, P.J. Goodman, J.S. Ungerleider, W.A. Emerson, D.C. Tormey, J.H. Glick, et al., Levamisole and fluorouracil for adjuvant therapy of resected colon carcinoma, The New England journal of medicine, 322 (1990) 352-358.

[37] J.A. Martenson, G. Hyland, C.G. Moertel, J.A. Mailliard, J.R. O'Fallon, R.T. Collins, R.F. Morton, H.H. Tewfik, R.L. Moore, A.R. Frank, R.E. Urias, R.L. Deming, Olsalazine is contraindicated during pelvic radiation therapy: Results of a double-blind, randomized clinical trial, International Journal of Radiation Oncology ${ }^{*}$ Biology ${ }^{*}$ Physics, 35 (1996) 299-303.

[38] C.G. Moertel, T.R. Fleming, J.S. Macdonald, D.G. Haller, J.A. Laurie, Hepatic toxicity associated with fluorouracil plus levamisole adjuvant therapy, Journal of Clinical Oncology, 11 (1993) 2386-2390.

[39] A. Moriarity, J. O'Sullivan, J. Kennedy, B. Mehigan, P. McCormick, Current targeted therapies in the treatment of advanced colorectal cancer: a review, Therapeutic Advances in Medical Oncology, 8 (2016) 276-293.

[40] A. Prat, E. Casado, J. Cortes, New approaches in angiogenic targeting for colorectal cancer, World J Gastroenterol, 13 (2007) 5857-5866.

[41] S. De Dosso, C. Sessa, P. Saletti, Adjuvant therapy for colon cancer: present and perspectives, Cancer treatment reviews, 35 (2009) 160-166.

[42] G. Recondo, Jr., E. Díaz-Cantón, M. de la Vega, M. Greco, G. Recondo, Sr., M.E. Valsecchi, Advances and new perspectives in the treatment of metastatic colon cancer, World Journal of Gastrointestinal Oncology, 6 (2014) 211-224.

[43] L. Migliore, F. Migheli, R. Spisni, F. Coppede, Genetics, cytogenetics, and epigenetics of colorectal cancer, Journal of biomedicine \& biotechnology, 2011 (2011) 792362.

[44] P. Gervaz, P. Bucher, P. Morel, Two colons-two cancers: paradigm shift and clinical implications, Journal of surgical oncology, 88 (2004) 261-266.

[45] E. Half, D. Bercovich, P. Rozen, Familial adenomatous polyposis, Orphanet journal of rare diseases, 4 (2009) 22. 
[46] K.W. Jasperson, T.M. Tuohy, D.W. Neklason, R.W. Burt, Hereditary and familial colon cancer, Gastroenterology, 138 (2010) 2044-2058.

[47] P. Galiatsatos, W.D. Foulkes, Familial Adenomatous Polyposis, Am J Gastroenterol, 101 (2006) 385-398.

[48] P. Polakis, The adenomatous polyposis coli (APC) tumor suppressor, Biochimica et Biophysica Acta (BBA) - Reviews on Cancer, 1332 (1997) F127-F147.

[49] K. Aoki, M.M. Taketo, Adenomatous polyposis coli (APC): a multi-functional tumor suppressor gene, Journal of cell science, 120 (2007) 3327-3335.

[50] A. Sameer, Colorectal Cancer: Molecular Mutations and Polymorphisms, Frontiers in Oncology, 3 (2013).

[51] M.L. Bisgaard, K. Fenger, S. Bulow, E. Niebuhr, J. Mohr, Familial adenomatous polyposis (FAP): frequency, penetrance, and mutation rate, Human mutation, 3 (1994) 121-125.

[52] M.L. Falcone Ferreyra, S.P. Rius, P. Casati, Flavonoids: biosynthesis, biological functions, and biotechnological applications, Frontiers in Plant Science, 3 (2012) 222.

[53] J.B. Harborne, C.A. Williams, Advances in flavonoid research since 1992, Phytochemistry, 55 (2000) 481-504.

[54] B. Yousuf, K. Gul, A.A. Wani, P. Singh, Health Benefits of Anthocyanins and Their Encapsulation for Potential Use in Food Systems: A Review, Crit Rev Food Sci, 56 (2016) 2223-2230.

[55] C.R. Welch, Q. Wu, J.E. Simon, Recent Advances in Anthocyanin Analysis and Characterization, Current analytical chemistry, 4 (2008) 75-101.

[56] R.L. Prior, X. Wu, Anthocyanins: Structural characteristics that result in unique metabolic patterns and biological activities, Free Radical Research, 40 (2006) 10141028.

[57] M. Landi, M. Tattini, K.S. Gould, Multiple functional roles of anthocyanins in plantenvironment interactions, Environmental and Experimental Botany, 119 (2015) 4-17.

[58] H. Kausar, J. Jeyabalan, F. Aqil, D. Chabba, J. Sidana, I.P. Singh, R.C. Gupta, Berry anthocyanidins synergistically suppress growth and invasive potential of human nonsmall-cell lung cancer cells, Cancer Lett, 325 (2012) 54-62.

[59] D. Del Rio, G. Borges, A. Crozier, Berry flavonoids and phenolics: bioavailability and evidence of protective effects, The British journal of nutrition, 104 Suppl 3 (2010) S6790 .

[60] K.S. Gould, C. Lister, Flavonoid Functions in Plants, in: O.M. Andersen, K.R. Markham (Eds.) FLAVONOIDS Chemistry, Biochemistry and Applications

CRC Press, Boca Raton, 2006, pp. 397-442. 
[61] A. Scalbert, G. Williamson, Dietary intake and bioavailability of polyphenols, The Journal of nutrition, 130 (2000) 2073s-2085s.

[62] J.M. Gee, M.S. DuPont, M.J. Rhodes, I.T. Johnson, Quercetin glucosides interact with the intestinal glucose transport pathway, Free radical biology \& medicine, 25 (1998) 19-25.

[63] T. Miyazawa, K. Nakagawa, M. Kudo, K. Muraishi, K. Someya, Direct intestinal absorption of red fruit anthocyanins, cyanidin-3-glucoside and cyanidin-3,5diglucoside, into rats and humans, J Agric Food Chem, 47 (1999) 1083-1091.

[64] S. Talavéra, C. Felgines, O. Texier, C. Besson, A. Gil-Izquierdo, J.-L. Lamaison, C. Rémésy, Anthocyanin Metabolism in Rats and Their Distribution to Digestive Area, Kidney, and Brain, Journal of Agricultural and Food Chemistry, 53 (2005) 3902-3908.

[65] A.R. Rechner, C. Kroner, Anthocyanins and colonic metabolites of dietary polyphenols inhibit platelet function, Thrombosis Research, 116 (2005) 327-334.

[66] N. Katsube, K. Iwashita, T. Tsushida, K. Yamaki, M. Kobori, Induction of apoptosis in cancer cells by Bilberry (Vaccinium myrtillus) and the anthocyanins, J Agric Food Chem, 51 (2003) 68-75.

[67] C. Zhao, M.M. Giusti, M. Malik, M.P. Moyer, B.A. Magnuson, Effects of commercial anthocyanin-rich extracts on colonic cancer and nontumorigenic colonic cell growth, $\mathrm{J}$ Agric Food Chem, 52 (2004) 6122-6128.

[68] D.Y. Shin, W.S. Lee, J.N. Lu, M.H. Kang, C.H. Ryu, G.Y. Kim, H.S. Kang, S.C. Shin, Y.H. Choi, Induction of apoptosis in human colon cancer HCT-116 cells by anthocyanins through suppression of Akt and activation of p38-MAPK, International journal of oncology, 35 (2009) 1499-1504.

[69] N. Karthi, T. Kalaiyarasu, S. Kandakumar, P. Mariyappan, V. Manju, Pelargonidin induces apoptosis and cell cycle arrest via a mitochondria mediated intrinsic apoptotic pathway in HT29 cells, RSC Advances, 6 (2016) 45064-45076.

[70] J.-M. Yun, F. Afaq, N. Khan, H. Mukhtar, Delphinidin, an Anthocyanidin in Pigmented Fruits and Vegetables, Induces Apoptosis and Cell Cycle Arrest in Human Colon Cancer HCT116 Cells, Molecular carcinogenesis, 48 (2009) 260-270.

[71] M.R. Webb, K. Min, S.E. Ebeler, Anthocyanin Interactions with DNA: Intercalation, Topoisomerase I Inhibition and Oxidative Reactions, Journal of food biochemistry, 32 (2008) 576-596.

[72] M.Y. Park, J.M. Kim, J.S. Kim, M.G. Choung, M.K. Sung, Chemopreventive Action of Anthocyanin-rich Black Soybean Fraction in APC (Min/+) Intestinal Polyposis Model, Journal of cancer prevention, 20 (2015) 193-201.

[73] H. Cai, T.H. Marczylo, N. Teller, K. Brown, W.P. Steward, D. Marko, A.J. Gescher, Anthocyanin-rich red grape extract impedes adenoma development in the Apc(Min) mouse: pharmacodynamic changes and anthocyanin levels in the murine biophase, European journal of cancer (Oxford, England : 1990), 46 (2010) 811-817. 
[74] L. Li, L. Wang, Z. Wu, L. Yao, Y. Wu, L. Huang, K. Liu, X. Zhou, D. Gou, Anthocyaninrich fractions from red raspberries attenuate inflammation in both RAW264.7 macrophages and a mouse model of colitis, Scientific reports, 4 (2014) 6234.

[75] D. Cooke, M. Schwarz, D. Boocock, P. Winterhalter, W.P. Steward, A.J. Gescher, T.H. Marczylo, Effect of cyanidin-3-glucoside and an anthocyanin mixture from bilberry on adenoma development in the ApcMin mouse model of intestinal carcinogenesis-relationship with tissue anthocyanin levels, International journal of cancer, 119 (2006) 2213-2220.

[76] E.J. Freireich, E.A. Gehan, D.P. Rall, L.H. Schmidt, H.E. Skipper, Quantitative comparison of toxicity of anticancer agents in mouse, rat, hamster, dog, monkey, and man, Cancer chemotherapy reports, 50 (1966) 219-244.

[77] S. Thomasset, D.P. Berry, H. Cai, K. West, T.H. Marczylo, D. Marsden, K. Brown, A. Dennison, G. Garcea, A. Miller, D. Hemingway, W.P. Steward, A.J. Gescher, Pilot study of oral anthocyanins for colorectal cancer chemoprevention, Cancer prevention research (Philadelphia, Pa.), 2 (2009) 625-633.

[78] R.A. Mentor-Marcel, G. Bobe, C. Sardo, L.S. Wang, C.T. Kuo, G. Stoner, N.H. Colburn, Plasma cytokines as potential response indicators to dietary freeze-dried black raspberries in colorectal cancer patients, Nutrition and cancer, 64 (2012) 820825.

[79] L.S. Wang, M. Arnold, Y.W. Huang, C. Sardo, C. Seguin, E. Martin, T.H. Huang, K. Riedl, S. Schwartz, W. Frankel, D. Pearl, Y. Xu, J. Winston, 3rd, G.Y. Yang, G. Stoner, Modulation of genetic and epigenetic biomarkers of colorectal cancer in humans by black raspberries: a phase I pilot study, Clinical cancer research : an official journal of the American Association for Cancer Research, 17 (2011) 598-610.

[80] S. Roth, M.R. Spalinger, C. Gottier, L. Biedermann, J. Zeitz, S. Lang, A. Weber, G. Rogler, M. Scharl, Bilberry-Derived Anthocyanins Modulate Cytokine Expression in the Intestine of Patients with Ulcerative Colitis, PloS one, 11 (2016) e0154817.

[81] L. Biedermann, J. Mwinyi, M. Scharl, P. Frei, J. Zeitz, G.A. Kullak-Ublick, S.R. Vavricka, M. Fried, A. Weber, H.U. Humpf, S. Peschke, A. Jetter, G. Krammer, G. Rogler, Bilberry ingestion improves disease activity in mild to moderate ulcerative colitis - an open pilot study, Journal of Crohn's \& colitis, 7 (2013) 271-279.

[82] S. Kamiloglu, E. Capanoglu, C. Grootaert, J. Van Camp, Anthocyanin Absorption and Metabolism by Human Intestinal Caco-2 Cells--A Review, International journal of molecular sciences, 16 (2015) 21555-21574.

[83] C. Thery, L. Zitvogel, S. Amigorena, Exosomes: composition, biogenesis and function, Nat Rev Immunol, 2 (2002) 569-579.

[84] R.M. Johnstone, A. Bianchini, K. Teng, Reticulocyte maturation and exosome release: transferrin receptor containing exosomes shows multiple plasma membrane functions, Blood, 74 (1989) 1844-1851. 
[85] S.R. Vaiselbuh, Exosomes in Cancer Research, Cancer Research Frontiers, 1 (2015) 11-24.

[86] J. Zhang, S. Li, L. Li, M. Li, C. Guo, J. Yao, S. Mi, Exosome and Exosomal MicroRNA: Trafficking, Sorting, and Function, Genomics, Proteomics \& Bioinformatics, 13 (2015) 17-24.

[87] J. Kowal, M. Tkach, C. Thery, Biogenesis and secretion of exosomes, Current opinion in cell biology, 29 (2014) 116-125.

[88] G. Raposo, W. Stoorvogel, Extracellular vesicles: exosomes, microvesicles, and friends, The Journal of cell biology, 200 (2013) 373-383.

[89] C. Théry, M. Boussac, P. Véron, P. Ricciardi-Castagnoli, G. Raposo, J. Garin, S. Amigorena, Proteomic Analysis of Dendritic Cell-Derived Exosomes: A Secreted Subcellular Compartment Distinct from Apoptotic Vesicles, The Journal of Immunology, 166 (2001) 7309-7318.

[90] B.K. Thakur, H. Zhang, A. Becker, I. Matei, Y. Huang, B. Costa-Silva, Y. Zheng, A. Hoshino, H. Brazier, J. Xiang, C. Williams, R. Rodriguez-Barrueco, J.M. Silva, W. Zhang, S. Hearn, O. Elemento, N. Paknejad, K. Manova-Todorova, K. Welte, J. Bromberg, H. Peinado, D. Lyden, Double-stranded DNA in exosomes: a novel biomarker in cancer detection, Cell Res, 24 (2014) 766-769.

[91] H. Valadi, K. Ekstrom, A. Bossios, M. Sjostrand, J.J. Lee, J.O. Lotvall, Exosomemediated transfer of mRNAs and microRNAs is a novel mechanism of genetic exchange between cells, Nature cell biology, 9 (2007) 654-659.

[92] A. Clayton, J.P. Mitchell, J. Court, M.D. Mason, Z. Tabi, Human tumor-derived exosomes selectively impair lymphocyte responses to interleukin-2, Cancer research, 67 (2007) 7458-7466.

[93] C. Thery, Exosomes: secreted vesicles and intercellular communications, F1000 biology reports, 3 (2011) 15.

[94] I. Parolini, C. Federici, C. Raggi, L. Lugini, S. Palleschi, A. De Milito, C. Coscia, E. lessi, M. Logozzi, A. Molinari, M. Colone, M. Tatti, M. Sargiacomo, S. Fais, Microenvironmental $\mathrm{pH}$ is a key factor for exosome traffic in tumor cells, The Journal of biological chemistry, 284 (2009) 34211-34222.

[95] R. Munagala, F. Aqil, J. Jeyabalan, R.C. Gupta, Bovine milk-derived exosomes for drug delivery, Cancer Lett, 371 (2016) 48-61.

[96] F. Aqil, H. Kausar, A.K. Agrawal, J. Jeyabalan, A.H. Kyakulaga, R. Munagala, R. Gupta, Exosomal formulation enhances therapeutic response of celastrol against lung cancer, Experimental and molecular pathology, 101 (2016) 12-21.

[97] A.K. Agrawal, F. Aqil, J. Jeyabalan, W.A. Spencer, J. Beck, B.W. Gachuki, S.S. Alhakeem, K. Oben, R. Munagala, S. Bondada, R.C. Gupta, Milk-derived exosomes for oral delivery of paclitaxel, Nanomedicine : nanotechnology, biology, and medicine, (2017). 
[98] C.A. Schneider, W.S. Rasband, K.W. Eliceiri, NIH Image to ImageJ: 25 years of image analysis, Nat Meth, 9 (2012) 671-675.

[99] G. Zhang, B. Svenungsson, A. Karnell, A. Weintraub, Prevalence of enterotoxigenic Bacteroides fragilis in adult patients with diarrhea and healthy controls, Clinical infectious diseases : an official publication of the Infectious Diseases Society of America, 29 (1999) 590-594.

[100] K.-J. Rhee, S. Wu, X. Wu, D.L. Huso, B. Karim, A.A. Franco, S. Rabizadeh, J.E. Golub, L.E. Mathews, J. Shin, R.B. Sartor, D. Golenbock, A.R. Hamad, C.M. Gan, F. Housseau, C.L. Sears, Induction of Persistent Colitis by a Human Commensal, Enterotoxigenic Bacteroides fragilis, in Wild-Type C57BL/6 Mice, Infection and immunity, 77 (2009) 1708-1718.

[101] S. Wu, J. Powell, N. Mathioudakis, S. Kane, E. Fernandez, C.L. Sears, Bacteroides fragilis enterotoxin induces intestinal epithelial cell secretion of interleukin-8 through mitogen-activated protein kinases and a tyrosine kinase-regulated nuclear factorkappaB pathway, Infection and immunity, 72 (2004) 5832-5839.

[102] T. Gu, M. De Jesus, H.C. Gallagher, T.P. Burris, N.K. Egilmez, Oral IL-10 suppresses colon carcinogenesis via elimination of pathogenicCD4+ T-cells and induction of antitumor CD8+ T-cell activity, Oncolmmunology, (2017) e1319027.

[103] A.Y. Chung, Q. Li, S.J. Blair, M. De Jesus, K.L. Dennis, C. LeVea, J. Yao, Y. Sun, T.F. Conway, L.P. Virtuoso, N.G. Battaglia, S. Furtado, E. Mathiowitz, N.J. Mantis, K. Khazaie, N.K. Egilmez, Oral interleukin-10 alleviates polyposis via neutralization of pathogenic T-regulatory cells, Cancer research, 74 (2014) 5377-5385.

[104] R. Munagala, F. Aqil, J. Jeyabalan, A.K. Agrawal, A.M. Mudd, A.H. Kyakulaga, I.P. Singh, M.V. Vadhanam, R.C. Gupta, Exosomal formulation of anthocyanidins against multiple cancer types, Cancer Lett, 393 (2017) 94-102.

[105] H.S. Aiyer, C. Srinivasan, R.C. Gupta, Dietary berries and ellagic acid diminish estrogen-mediated mammary tumorigenesis in $\mathrm{ACl}$ rats, Nutrition and cancer, 60 (2008) 227-234.

[106] F. Aqil, J. Jeyabalan, H. Kausar, R. Munagala, I.P. Singh, R. Gupta, Lung cancer inhibitory activity of dietary berries and berry polyphenolics, Journal of Berry Research, 6 (2016) 105-114.

[107] D.X. Hou, T. Yanagita, T. Uto, S. Masuzaki, M. Fujii, Anthocyanidins inhibit cyclooxygenase-2 expression in LPS-evoked macrophages: structure-activity relationship and molecular mechanisms involved, Biochem Pharmacol, 70 (2005) 417425.

[108] D. Marko, N. Puppel, Z. Tjaden, S. Jakobs, G. Pahlke, The substitution pattern of anthocyanidins affects different cellular signaling cascades regulating cell proliferation, Molecular nutrition \& food research, 48 (2004) 318-325.

[109] M. Renis, L. Calandra, C. Scifo, B. Tomasello, V. Cardile, L. Vanella, R. Bei, L. La Fauci, F. Galvano, Response of cell cycle/stress-related protein expression and DNA 
damage upon treatment of $\mathrm{CaCo} 2$ cells with anthocyanins, The British journal of nutrition, 100 (2008) 27-35.

[110] N. Kiuchi, K. Nakajima, M. Ichiba, T. Fukada, M. Narimatsu, K. Mizuno, M. Hibi, T. Hirano, STAT3 is required for the gp130-mediated full activation of the c-myc gene, The Journal of experimental medicine, 189 (1999) 63-73.

[111] H.J. Choi, J.S. Han, Overexpression of phospholipase D enhances Bcl-2 expression by activating STAT3 through independent activation of ERK and p38MAPK in HeLa cells, Bba-Mol Cell Res, 1823 (2012) 1082-1091.

[112] R. Catlett-Falcone, T.H. Landowski, M.M. Oshiro, J. Turkson, A. Levitzki, R. Savino, G. Ciliberto, L. Moscinski, J.L. Fernandez-Luna, G. Nunez, W.S. Dalton, R. Jove, Constitutive activation of Stat3 signaling confers resistance to apoptosis in human U266 myeloma cells, Immunity, 10 (1999) 105-115.

[113] K. Leslie, C. Lang, G. Devgan, J. Azare, M. Berishaj, W. Gerald, Y.B. Kim, K. Paz, J.E. Darnell, C. Albanese, T. Sakamaki, R. Pestell, J. Bromberg, Cyclin D1 is transcriptionally regulated by and required for transformation by activated signal transducer and activator of transcription 3, Cancer research, 66 (2006) 2544-2552.

[114] T. Gritsko, A. Williams, J. Turkson, S. Kaneko, T. Bowman, M. Huang, S. Nam, I. Eweis, N. Diaz, D. Sullivan, S. Yoder, S. Enkemann, S. Eschrich, J.H. Lee, C.A. Beam, J. Cheng, S. Minton, C.A. Muro-Cacho, R. Jove, Persistent activation of stat3 signaling induces survivin gene expression and confers resistance to apoptosis in human breast cancer cells, Clinical cancer research : an official journal of the American Association for Cancer Research, 12 (2006) 11-19.

[115] R.L. Carpenter, H.W. Lo, STAT3 Target Genes Relevant to Human Cancers, Cancers (Basel), 6 (2014) 897-925.

[116] A.E. Moran, D.H. Hunt, S.H. Javid, M. Redston, A.M. Carothers, M.M. Bertagnolli, Apc deficiency is associated with increased Egfr activity in the intestinal enterocytes and adenomas of C57BL/6J-Min/+ mice, The Journal of biological chemistry, 279 (2004) 43261-43272. 


\title{
CURRICULUM VITAE
}

\author{
Ashley Marie Mudd \\ Graduate Research Assistant \\ Department of Pharmacology and Toxicology \\ 580 S. Hancock St. \\ Louisville, KY 40292
}

\author{
EDUCATION: \\ University of Louisville \\ M.S. and Ph.D. in Pharmacology and Toxicology \\ Cumulative Grade Point Average: 3.8 \\ 2014-present \\ Brown University \\ A.M. in Chemistry \\ Cumulative Grade Point Average: 3.8 \\ Graduation Month/Year: June 2012 \\ Wilson College \\ Chemistry (with honors in the major) \& Spanish Double Major \\ Biology, Business and Economics Minors \\ Cumulative Grade Point Average: 3.9 \\ Graduation Month/Year: June 2009 \\ Mercersburg Academy \\ Graduation Month/Year: May 2005
}

\section{RESEARCH AND PROFESSIONAL EXPERIENCE:}

Graduate Research Assistant, University of Louisville (2014-present)

Working in the lab of Dr. Ramesh Gupta, my research focuses on utilizing Anthos and ExoAnthos in the treatment of breast and colorectal cancer as well as familial adenomatous polyposis.

Scientist and Project lead, NuLabel Technologies (10/2012-06/2014)

Responsible for developing both the research and business aspects of my project. During this time, I also co-authored three patents. 
Visiting Scholar, Department of Molecular Biology, Cell Biology and Biochemistry, Brown University (05/2013-06/2014)

Research focusing on discovering the biological phosphorylation networks in immune cells, especially $T$ cell signaling pathway quantitative phosphoproteomic study.

Research Assistant, Department of Chemistry, Brown University (2010)

My research focused on profiling cell wall carbohydrate changes using GC-MS during pollen development. I was responsible for developing extraction, sample preparation and GC-MS methods.

Honors Undergraduate Research, Wilson College (2008-2009)

Independent research project that focused on investigating the relationship between levels of $\beta$-carotene and Tetrachloroisophthalonitrile Fungicide Residue levels in D.carota and $R$. sativus.

Internship with the Crawford Beck Vineyard Inc. (Summer 2008)

Responsible for creating a vineyard expansion plan involving the selection of variety, clone, rootstock, site, and trellising system based upon market forces, soil chemistry, degree growing days, as well as other factors.

\section{TEACHING EXPERIENCE:}

Teaching Assistant Undergraduate Organic Chemistry CHEM 350 and CHEM 360 Brown University, Fall 2010-Spring 2012

Responsible for teaching 1-2 laboratory classes per week for the undergraduate first (CHEM 350) and second semester (CHEM 360) organic chemistry classes. During this time, I have instructed students how to use GC, prepare and run basic gravity column chromatography, perform fractional, simple and steam distillations, TLC, IR, refractometer, melting point apparatus and how to interpret the results from the above. I have also helped students interpret Mass Spectra and NMR (proton and ${ }^{13} \mathrm{C}$ ) spectra, as well as how to prepare the samples for each method. Furthermore, I have also been responsible for grading lab reports, lab quizzes, student laboratory notebooks, and lecture exams.

Peer Teacher First Year Seminar Solving 21st Century Problems: Theory to Practice, Honors Section

Wilson College, Fall 2007

Worked with faculty member to develop the course, co-taught lectures, and participated in grading.

\section{Peer Teacher First Year Seminar on Sustainable Living, Honors Section \\ Wilson College, Fall 2006 \\ Worked with faculty member from the Biology department to develop the course, co-taught lectures, and participated in grading.}

ACADEMIC AND PROFESSIONAL HONORS:

-University of Louisville $1^{\text {st }}$ place Louisville Women in Medicine and Science Research Award (Fall 2015) 
-University of Louisville IPIBS Fellowship recipient (Fall 2014-Summer 2016)

-Honors in Chemistry

-Wilson College Davison Greenawalt Grove Award for Distinction in Senior Research in the Physical and Life Sciences (Spring 2009)

-Wilson College Margaret Strode Haines Award for "outstanding qualities of scholarship, interest in the humanities and strength of mind, body and spirit" (Spring 2009)

-Phi Beta Kappa honor society

-Wilson College Mary-Eleanor Maule Travel Grant (Spring 2009)

-Grant from the Pennsylvania Academy of Science for my Senior Research project entitled: An Inquiry into the Existence of a Relationship between $\beta$-carotene and Tetrachloroisophthalonitrile Fungicide Residue levels in D.carota (2008-2009)

-Scholarship to attend the 2008 International Diffuse Reflectance Conference (IDRC)

-Peer Teacher Recognition Award (Spring 2008)

-Wilson College Mary-Eleanor Maule Travel Grant for Spanish (Spring 2008)

-National Science Foundation SEBCLAR scholarship (Fall 2007)

-Scholarship to attend Mises University at the Ludwig von Mises Institute of Austrian Economics (Summer 2007)

-Liberty Fund weekend colloquia (Fall 2006-Spring 2009)

-Wilson College Robert Shannon McElwain Prize in Mathematics awarded (Spring 2007)

-Wilson College Organic Chemistry Award (Spring 2007)

-Wilson College Peer Teacher Recognition Award (Spring 2007)

-2006-2007 Intercollegiate Studies Institute Honors Fellow

-Wilson College Phoenix Scholar (2006-2009)

-Wilson College's Honors Program (2006-2009)

-College Board Advanced Placement Scholar with Distinction (Spring 2005)

-Mercersburg Academy Colonel Wills First Place Prize in the Study of Economics (Spring 2005)

-Maintained Honors-High Honors Academic Status while attending The Mercersburg Academy (Spring 2005) 


\section{PUBLICATIONS:}

Munagala, R., Aqil, F., Jeyabalan, J., Agrawal, A., Mudd, A. M., Kyakulaga, A. H., Vadhanam, M. V., Gupta, R. C. Exosomal formulation of anthocyanidins against multiple cancer types. Cancer Lett., 393 (2017) pp. 94-102

Belmont, J., Gu, T., Mudd, A., Salomon, A. A PLC-ү1 Feedback Pathway Regulates Lck Substrate Phosphorylation at the T Cell Receptor and SLP-76 Complex. (manuscript accepted by J. Proteome Res on 06/23/17)

\section{PATENTS:}

Mudd, A.M., Munnelly, H., Lux, B., Shear Stress-Resistant Systems and Uses Thereof. Patent US20160331087 A1 (Issued Nov 17, 2016)

Cho, D., Mudd, A.M., Sonshine, D., Two-Component Hybrid Labeling System for Use in Repeat Labeling. U.S. Patent US20140072748 A1 Sept 12, 2013 (Issued March 13, 2014)

Lux, B., Mudd, A.M., Munnelly, H., Articles de conditionnement refermables et leurs procédés de fabrication et d'utilisation. WO 2015073566 A1 Nov 12, 2014. (Issued May $21,2015)$

\section{ABSTRACTS/POSTER PRESENTATIONS:}

Mudd, A. M., Gu, T., Jeyabalan, J., Munagala, R., Egilmez., N.K., Gupta, R. C. (2017, March)Prevention and Treatment of Colorectal Cancer by BilberryDerived Anthocyanidin $s$ (Anthos) and Nano-Anthos. Abstract submitted for poster session at Berry Health Benefits Symposium, Pismo Beach, CA.

Mudd, A. M., Gu, T., Jeyabalan, J., Munagala, R., Egilmez., N. K., Gupta, R. C. (2016, October) Prevention and treatment of familial adenomatous polyposis (FAP) and colorectal cancer by bilberry-derived anthocyanidins Abstract submitted for poster session at annual Research Louisville, Louisville, KY.

Mudd, A. M., Munagala, R., Gupta, R. C. (2015, October) Exosomal formulations enhance therapeutic response of anthocyanidins against breast cancer. Abstract submitted for poster session at annual Research Louisville, Louisville, KY.

\section{Professional Memberships}

American Chemical Society

Pennsylvania Academy of Science

Phi Beta Kappa Honor Society 